\title{
Impact of Argo Observation on the Regional Ocean Reanalysis of China Coastal Waters and Adjacent Seas: A Twin-Experiment Study
}

\author{
Caixia Shao, ${ }^{1,2}$ Lili Xuan, ${ }^{2}$ Yingzhi Cao, ${ }^{2}$ Xiaojian Cui, ${ }^{2}$ and Siyu Gao ${ }^{2}$ \\ ${ }^{1}$ National University of Defense Technology, Hunan, Changsha 410073, China \\ ${ }^{2}$ Key Laboratory of Marine Environmental Information Technology, SOA, National Marine Data and Information Service, \\ Tianjin 300171, China
}

Correspondence should be addressed to Caixia Shao; shaocx@163.com

Received 18 December 2014; Revised 10 February 2015; Accepted 10 March 2015

Academic Editor: Shaoqing Zhang

Copyright @ 2015 Caixia Shao et al. This is an open access article distributed under the Creative Commons Attribution License, which permits unrestricted use, distribution, and reproduction in any medium, provided the original work is properly cited.

\begin{abstract}
A regional ocean reanalysis system of China coastal waters and adjacent seas, called CORA (China ocean reanalysis), has been recently developed at the National Marine Data and Information Service (NMDIS). In this study, based on CORA, the impact of Argo profiles on the regional reanalysis is evaluated using a twin-experiment approach. It is found that, by assimilating Argo observations, the reanalysis quality is much improved: the root mean square (RMS) error of temperature and salinity can be further reduced by about $10 \%$ and the RMS error of current can be further reduced by $18 \%$, compared to the case only assimilating conventional in situ temperature and salinity observations. Consistent with the unique feature of Argo observations, the temperature is improved in all levels and the largest improvement of salinity happens in the deep ocean. Argo profile data have a significant impact on the regional ocean reanalysis through improvements of both hydrographic and dynamic fields.
\end{abstract}

\section{Introduction}

With the gradual increasing of global ocean Argo (Array for Real-Time Geostrophic Oceanography) profile [1], a lot of researches on Argo application have been carried out by scientists and many useful results have been achieved. Argo data especially have been widely used in operational oceanography, such as ocean data assimilation, forecast, and reanalysis [2-5].

Therefore, it is also necessary to evaluate the impact of Argo on ocean data assimilation. Many research works have addressed this issue. Studies related to this topic can be roughly divided into two classes. The first class is known as Observing System Experiments (OSEs). In these experiments, an ocean analysis, in which all available data are assimilated, serves as a reference. And permutations of combinations of the available observation systems are used in an analysis, in which one observational system is excluded from the analysis, so providing an estimate of the impact of the omitted observational system by comparing the analysis with the reference. In this field lots of works have been done to evaluate the Argo impact. For example, Vidard et al. [6] assessed the relative importance of the tropical in situ mooring arrays (TAO, TRITON, and PIRATA), XBTs, and the developing Argo float network on global ocean analysis and seasonal forecasts, showing a major role for the moorings and in some ways a smaller contribution from Argo than might have been expected. Balmaseda et al. [7] assessed the impact of Argo on ECMWF operational ocean analyses and evaluated the information content of Argo temperature and salinity data, gauged in terms of influence on the ocean state and the skill of seasonal forecasts. Oke and Schiller [8] assessed the relative importance of Argo temperature and salinity profiles, sea-surface temperature, and altimetric sea-level anomalies for constraining upper-ocean $T$ and $S$ properties and mesoscale variability of sea-level anomalies in an eddy resolving ocean reanalysis in the Australian region. Yan et al. [9] assessed the impacts of XBT, TAO, altimetry, and Argo observations on the tropical Pacific ocean data assimilation. Huang et al. [10] investigated the impact 
of Argo salinity profiles on the NCEP Global Ocean Data Assimilation System (GODAS) in the tropical Indian Ocean.

The second class is known as Observing System Simulation Experiments (OSSEs). The OSSE approach was first adopted by the meteorological community not only to assess the impact of observations but also to optimize the design of observing systems and observing networks in order to improve numerical weather predictions. Oceanographic applications to Argo impact assessment and Argo profile sampling strategy optimization have been reported by several literatures. For example, Schiller et al. [11] performed OSSE using OGCM output to assess sampling strategies for the Argo array in the Indian Ocean. Griffa et al. [12] and Raicich [13] quantitatively investigated the impact of assimilating temperature and salinity profiles from Argo floats in the Mediterranean Sea using the OSSE approach. Zhang et al. [14] show the potential of Argo profiles to initialize the Atlantic meridional overturning circulation (MOC) which is an important source of multidecadal climate variability and trends. Dunstone and Smith [15] investigated the impact of assimilating different amounts of atmosphere and ocean data, including Argo profile, on decadal climate prediction skill through a set of idealized model experiments and found that the upper $2000 \mathrm{~m}$ temperature and salinity observations currently provided by the Argo array of floats are potentially well suited to initializing decadal climate predictions.

However, most of the above literatures concentrate on the impact of Argo profiles on data assimilation for global ocean rather than for the marginal seas, such as the coastal waters of China and adjacent seas.

A regional ocean reanalysis experiment which is focused on the coastal waters of China and adjacent seas has already been started a few years ago by National Marine Data and Information Service (NMDIS). The present ocean reanalysis system (China ocean reanalysis, CORA) for this area is achieved, and a dataset package of sea surface height (SSH), three-dimensional (3D) temperature, salinity, and currents in this area (http://www.cmoc-china.cn/) is developed $[5,16]$.

In this paper, based on the CORA system, data assimilation identical twin-experiment approach used in OSSE technique is employed to evaluate the impact of Argo data on temperature, salinity, and current reanalysis results of China coastal waters and adjacent seas. The data assimilation identical twin-experiment approach is one of the useful methods to evaluate the impact of the ocean observation system $[14,17]$. But here we do not touch Argo observing systems optimal design which will be our future goal. Ocean dynamic model, ocean data assimilation scheme used in CORA, and twin-experiment configuration are described in the following section. Section 3 mainly discusses the impact of Argo on the ocean reanalysis of this area and conclusions are given in Section 4.

\section{Twin Experiment of Reanalysis}

The OSSE technique consists of identical twin experiments [13], in which data extracted from a reference model run is assimilated into other runs of the same model with different initial conditions. The convergence of the other runs towards the first one is measured to quantify the data assimilation effectiveness in driving the model with "wrong" initial conditions towards the reference, and the comparison between analyses with and without Argo profiles data assimilated can provide an estimate of impact of Argo profiles. All runs are driven by the same external forcing.

2.1. Ocean Dynamic Model. The NMDIS-developed parallel version of Princeton Ocean Model with generalized coordinate system (POMgcs) $[18,19]$ serves as the ocean dynamical model in CORA. The original version of POMgcs, known as POM (Princeton Ocean Model), has been widely used [20, 21]. Following $[22,23]$, the wave breaking parameterization of Mellor and Blumberg [24] is introduced into POMgcs to deepen the mixed temperature surface layer. The tidal generating potential and tidal open boundary condition of eight major tidal constituents $\left(M_{2}, S_{2}, N_{2}, K_{2}, K_{1}, O_{1}, P_{1}\right.$, and $Q_{1}$ ) are added to this model to simulate tidal effect.

The study area extends from $10^{\circ} \mathrm{S}$ to $52^{\circ} \mathrm{N}$ in latitude and from $99^{\circ} \mathrm{E}$ to $150^{\circ} \mathrm{E}$ in longitude. The model grid spacing is varied from $1 / 2^{\circ}$ to $1 / 8^{\circ}$ and the area with the highest horizontal resolution $1 / 8^{\circ}$ extends from $19^{\circ} \mathrm{N}$ to $33^{\circ} \mathrm{N}$ in latitude and from $117^{\circ} \mathrm{E}$ to $130^{\circ} \mathrm{E}$ in longitude. Due to the huge range and the complicated bathymetry of the study area, the hybrid coordinate of POMgcs is in use, in conformity with the study of Mellor et al. [18]. The $\sigma$-level vertical grid is used in the area with local depth less than $200 \mathrm{~m}$, that is, the continental shelf, to form a terrain-following vertical grid. While in the area with local depth greater than $200 \mathrm{~m}$, that is, slope area and deep sea area, in order to simulate satisfactorily the upper mixed layer and thermocline, most of the vertical levels at the upper and middle ocean are set to $z$-level, and at the level depth greater than 0.9 proportion of the local depth only a few vertical levels near seafloor are set to terrain-following $\sigma$-level to represent the seafloor preferably to avoid the stair-step effect. Coarse vertical level near seafloor can make the hydrostatic consistency criteria satisfied. There are 33 vertical levels with a maximum depth of $4500 \mathrm{~m}$. The vertical $z$-level grid is listed in Table 1 .

The twin experiment of reanalysis spanned four years from January 2005 to December 2008. SODA (Simple Ocean Data Assimilation) monthly-mean product of each year serves as the open boundary condition for sea surface height (SSH), temperature, salinity, and current. Wind field uses Quick Scatterometer (QuikSCAT) wind field of daily Level 3 data with the horizontal resolution being $1 / 4^{\circ}$. And heat flux field comes from the National Centers of Environment Prediction (NCEP) reanalysis version 1 product.

2.2. Ocean Data Assimilation Scheme. The ocean data assimilation scheme used in CORA is a sequential threedimensional variational (3D-Var) analysis scheme designed to assimilate temperature and salinity using a multigrid framework $[5,16]$. This sequential 3D-Var analysis scheme can extract long and short wavelength information in turn quickly from observations system and provide objective and accurate analysis. The basic idea of this data assimilation scheme can be referred to in [25-30]. In this study, 9 level grids are applied from $2 \times 2 \times 2$ (only one big cell containing 
TABLE 1: The vertical $z$-level grid list.

\begin{tabular}{lccccccccc}
\hline Level & Depth $(\mathrm{m})$ & Level & Depth $(\mathrm{m})$ & Level & Depth $(\mathrm{m})$ & Level & Depth $(\mathrm{m})$ & Level & Depth $(\mathrm{m})$ \\
\hline 1 & 2.5 & 8 & 125 & 15 & 450 & 22 & 1100 & 29 & 2500 \\
2 & 10 & 9 & 150 & 16 & 500 & 23 & 1200 & 30 & 3000 \\
3 & 20 & 10 & 200 & 17 & 600 & 24 & 1300 & 31 \\
4 & 30 & 11 & 250 & 18 & 700 & 25 & 1400 & 32 \\
5 & 50 & 12 & 300 & 19 & 800 & 26 & 1500 & 33 \\
6 & 75 & 13 & 350 & 20 & 900 & 27 & 1750 & 4500 \\
7 & 100 & 14 & 400 & 21 & 1000 & 28 & 2000 & \\
\hline
\end{tabular}

the whole study domain) to $257 \times 257 \times 33$ (the horizontal interval is about $0.2^{\circ} \times 0.24^{\circ}$, and the vertical resolution is the same as that of the model). The smooth penalty parameter, weighing how strong the smoothing term will be, is set to 0.005 . Square of the simulated observational error, which will be discussed in the next section, is used to specify the diagonal element of observational error covariance matrix, while the off-diagonal element is set to zero. Fifty iterations are employed to every level grid's optimization.

The basic idea proposed by Troccoli et al. [31] is employed to make salinity adjustment during temperature assimilation. In this scheme, the $T-S$ relation is basically conserved during the temperature data assimilation; and salinity measurements are assimilated to adjust the $T-S$ relation only if such measurements are available. Following Troccoli et al. [31], a latitudinal filter has been applied to the salinity increments so that the whole salinity increment is applied only within $30^{\circ}$ of the equator. Outside this region, the weight given to the salinity adjustment diminishes linearly to zero at latitudes poleward of north edge of model domain. This is done to avoid implementing the salinity correction scheme in areas where the stratification is weak and $S(z)$ persistence is more appropriate.

The assimilation is performed every day and a seven-day time window is used to incorporate as many observations as possible.

2.3. True Fields and "Observation" Construction. With the open boundary conditions and meteorological driving force described above and with CORA reanalysis of January 1, 2005 serving as the initial field, 4-year integration is carried out from January 2005 to December 2008 by using the NMDIS-developed parallel version of POMgcs. Then the 4year simulation results serve as the true fields for comparing the following twin-experiment reanalysis results to evaluate the impact of Argo on this regional reanalysis.

Following the method in [14], "observations" needed in reanalysis twin-experiment are constructed by interpolating the above true fields to the temporal and spatial information of real temperature or salinity observation networks, including Nansen bottle, conductivity-temperature-depth (CTD), and various bathythermograph (BT) and Argo profiles. It should be noted that CTD and Argo profiles may have both temperature and salinity observations, while the others profiles may only have temperature observations. And compared to CTD profiles, Argo profiles may be distributed relatively homogeneously. A Gaussian white noise with the mean and standard deviation being $0.0^{\circ} \mathrm{C}(0.0 \mathrm{psu})$ and $1.0^{\circ} \mathrm{C}(0.2 \mathrm{psu})$, respectively, is added to temperature (salinity) "observation" as random error simulation. The imposed white noise attempts to account for random measurement errors of the observing system. For simplicity, "observations" which have the temporal and spatial information of Nansen bottle, CTD, and variety of BT are called "conventional observations," and those with Argo temporal and spatial information are called "Argo observations." Distributions of "observations" used in reanalysis twin experiment from January 2005 to December 2008 are shown in Figure 1. It is found that dense "observations" in this study domain are mainly distributed around Japan, including Japan Sea and Kuroshio to the south of Japan. In other areas, except for some moored profiles which have many data, "observations" are scarcely distributed. In China coastal waters especially, including Bohai Sea (BS), Yellow Sea (YS), East China Sea (ECS), and South China Sea (SCS), most areas are measured only once per year. "Argo observations" are homogeneously distributed in the Pacific Ocean to the east of Ryukyu Island. Along with current, several Argos drifted to the west of Ryukyu Island and in 2008 several Argos drifted in the northern SCS.

2.4. Twin-Experiment Configuration. Three twin experiments are carried out to study the impact of Argo on temperature, salinity, and current reanalysis results of the China coastal waters and adjacent seas. They all use the setup ocean model described in Section 2.1 and data assimilation scheme described in Section 2.2 and are subject to the same meteorological driving force and open boundary condition as those used in construction of true field and all run for the period from January 2005 to December 2008. However, the initial condition is different from that of true field. Observational climatology of temperature and salinity field in August serves as the initial condition for the three twin experiments and the initial sea surface height and current field are obtained by one-year diagnostic spin-up using the same model. No "observation" is assimilated in Experiment 1; that is, Experiment 1 is a free run, while Experiment 2 only assimilates "conventional observations" and Experiment 3 assimilates all the "observations" including "conventional observations" and "Argo observations." The impact of satellite SST and SSHA on reanalysis is beyond the scope of this study, so no experiment assimilates satellite observations.

By comparing the twin-experiment daily results with the true fields, root mean square error (RMSE) for 4-year 


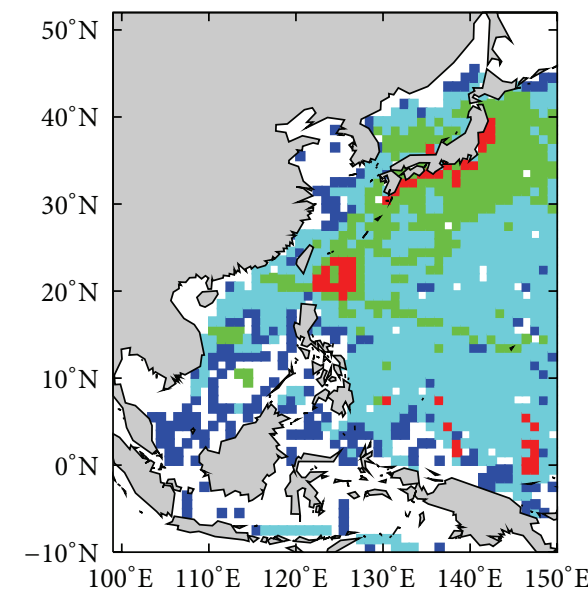

(a)

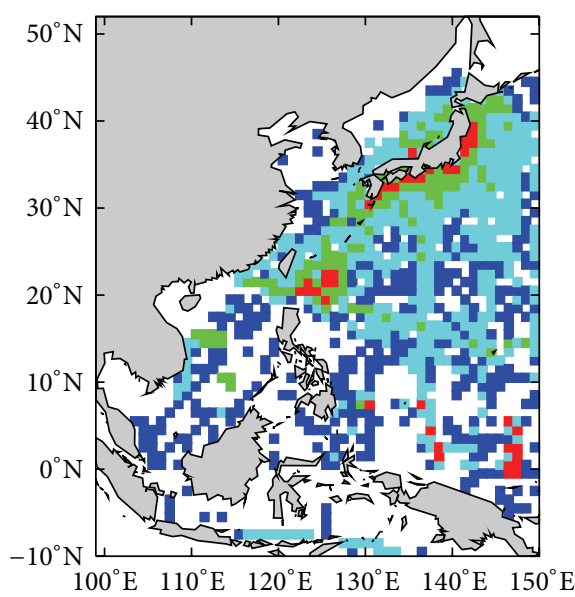

(c)

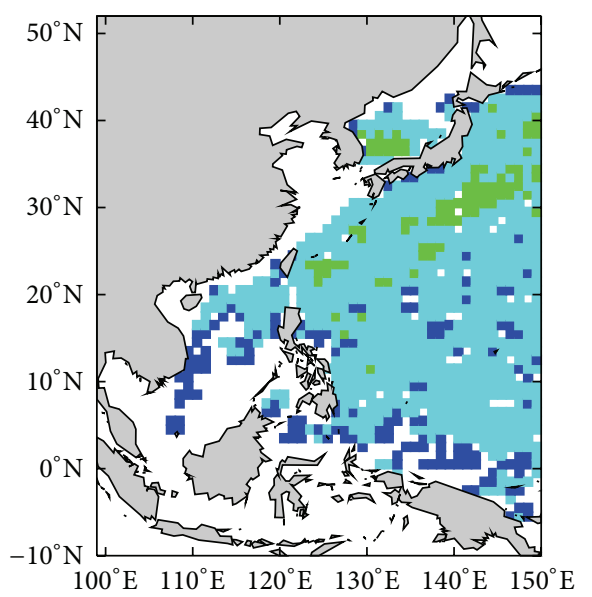
$\square 0$ to 0
- 1 to 4 - 5 to 48

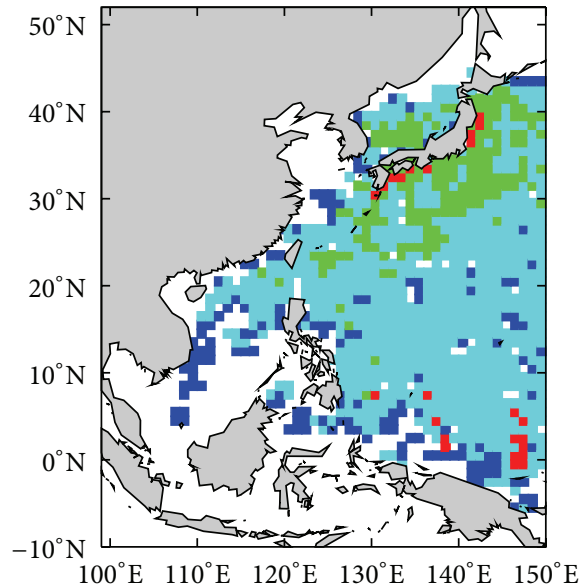

(b)

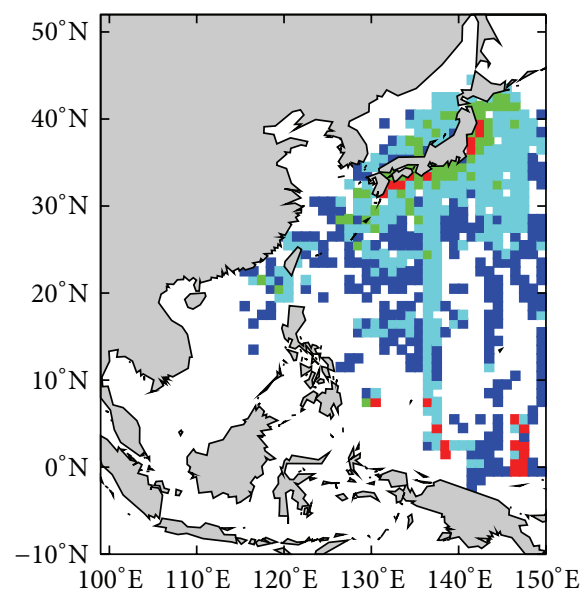

(d)

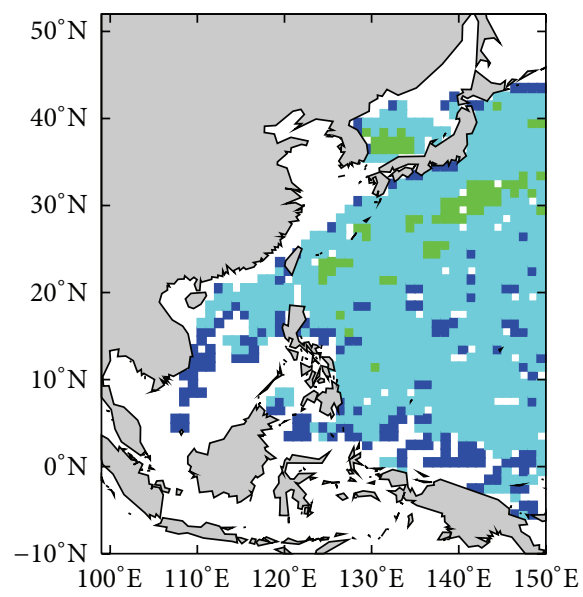
$\square 0$ to 0
- 1 to 4
- 49 to 200
- 201 to 21390

(f)

FIGURE 1: Distributions of "observations" used in reanalysis twin experiments from January 2005 to December 2008: (a), (c), and (e) are temperature "observations"; (b), (d), and (f) are salinity "observations." (a) and (b) are for all "observations"; (c) and (d) "conventional observations"; (e) and (f) "Argo observations." Color square represents the number of profiles. 
average over the whole domain RMSE_whole, horizontal distribution of RMSE RMSE_H, and vertical distribution of RMSE RMSE_V can be calculated using the following equations, and the impact of Argo on reanalysis of this study domain can be evaluated:

$$
\begin{aligned}
& \operatorname{RMSE\_ whole}(F)=\sqrt{\frac{\sum_{n=1}^{N M} \sum_{k=1}^{K M} \sum_{j=1}^{J M} \sum_{i=1}^{I M}\left[\left(F_{i, j, k, n}^{\mathrm{Exp}}-F_{i, j, k, n}^{\mathrm{True}}\right)^{2} \cdot \Delta x_{i, j, k} \cdot \Delta y_{i, j, k} \cdot \Delta z_{i, j, k} \cdot M_{i, j, k}\right]}{\sum_{n=1}^{N M} \sum_{k=1}^{K M} \sum_{j=1}^{J M} \sum_{i=1}^{I M}\left(\Delta x_{i, j, k} \cdot \Delta y_{i, j, k} \cdot \Delta z_{i, j, k} \cdot M_{i, j, k}\right)}}, \\
& \operatorname{RMSE} \_\mathrm{H}(F)_{i, j}=\sqrt{\frac{\sum_{n=1}^{N M} \sum_{k=1}^{K M}\left[\left(F_{i, j, k, n}^{\operatorname{Exp}}-F_{i, j, k, n}^{\text {True }}\right)^{2} \cdot \Delta x_{i, j, k} \cdot \Delta y_{i, j, k} \cdot \Delta z_{i, j, k} \cdot M_{i, j, k}\right]}{\sum_{n=1}^{N M} \sum_{k=1}^{K M}\left(\Delta x_{i, j, k} \cdot \Delta y_{i, j, k} \cdot \Delta z_{i, j, k} \cdot M_{i, j, k}\right)}}, \\
& \operatorname{RMSE} \_\mathrm{V}(F)_{k}=\sqrt{\frac{\sum_{n=1}^{N M} \sum_{j=1}^{J M} \sum_{i=1}^{I M}\left[\left(F_{i, j, k, n}^{\mathrm{Exp}}-F_{i, j, k, n}^{\mathrm{True}}\right)^{2} \cdot \Delta x_{i, j, k} \cdot \Delta y_{i, j, k} \cdot \Delta z_{i, j, k} \cdot M_{i, j, k}\right]}{\sum_{n=1}^{N M} \sum_{j=1}^{I M} \sum_{i=1}^{I M}\left(\Delta x_{i, j, k} \cdot \Delta y_{i, j, k} \cdot \Delta z_{i, j, k} \cdot M_{i, j, k}\right)}},
\end{aligned}
$$

where $F$ stands for temperature, salinity, $\mathrm{U}$ component, or $\mathrm{V}$ component of current; superscript Exp represents the result of different experiments and True the true field; $I M, J M, K M$, and $N M$ are the numbers of grid points of zonal, meridional, vertical directions and the number of reanalysis days, respectively; subscripts $i, j, k$, and $n$ are the grid indices of zonal, meridional, vertical, and temporal directions, respectively; $\Delta x, \Delta y$, and $\Delta z$ are the length of zonal, meridional, and vertical directions for one grid cell, and $M$ is a mask value with 1 representing wet grid and 0 representing dry grid.

\section{Impact of Argo on Ocean Reanalysis}

3.1. Impact of Argo on Temperature Reanalysis. Figures 2(a), 2(b), and 2(c) show the horizontal distribution of vertical averaged temperature RMSEs of the three twin experiments, respectively, using (2). Since no "observation" is assimilated in Experiment 1 and the initial field (climatological temperature in August) has big difference compared with the true field (CORA temperature of January 2005), the mean RMSE of temperature over whole domain is about $3.676^{\circ} \mathrm{C}$ using (1). The largest RMSEs appear in China coastal water, Thailand Bay, and Karimata Strait where few "observations" can support the analysis. Luzon Strait, area to the east of Taiwan, Japan Sea, and Equator area also have large RMSEs. By assimilating "conventional observations," temperature RMSE of Experiment 2 is obviously lower than that of Experiment 1 by about $40 \%$. By further assimilating "Argo observations," the temperature RMSE of Experiment 3 is lower than that of Experiment 2 by about 10\%; that is, the temperature RMS error of Experiment 3 is lowest among all three twin experiments. Figure 2(d) shows the difference of temperature RMSEs between Experiments 1 and 2, and Figure 2(e) shows that between Experiments 1 and 3. Therefore Figures 2(d) and 2(e) represent the improvement of Experiments 2 and 3 relative to 1, respectively. Figure 2(f) shows the difference of temperature RMSEs between Experiments 2 and 3, which represents the improvement of Experiment 3 relative to 2 .
Positive value means RMSE decreasing and reanalysis improving, and, on the contrary, negative value means reanalysis degenerating. It is found that the improved area of Experiment 2 compared to 1 includes Japan Sea, Kuroshio area, area to the east of Taiwan, north part of SCS, and Equator area where many "conventional observations" can support the analysis. In addition to the above improved area, the improved area of Experiment 3 compared to 1 is further enlarged, even to eastern boundary of this study domain (Figures 2(e) and 2(f)). Figure 3(a) gives the vertical structure of temperature RMS error of these three twin experiments using (3). Figures 3(b) and 3(c) represent the improvement of Experiments 2 and 3 relative to 1, respectively, and Figure 3(d) represents the improvement of Experiment 3 relative to 2. The main improvement of Experiment 2 with only "conventional observations" assimilated concentrates in the upper level, and there is somewhat degeneration beneath $2500 \mathrm{~m}$ level. Considering that there is big difference between "observations" and model background, data assimilation within the upper ocean may destroy the stratification in the ocean, and abnormal mixing may be generated in the ocean, which may result in the above degeneration beneath $2500 \mathrm{~m}$ level in Experiment 2 with only "conventional observations." However, the deep observations of Argo may compromise this problem. Therefore, with "Argo observation" assimilated, temperatures in all levels are improved (Figures 3(c) and 3(d)) although Argo only provides upper $2000 \mathrm{~m}$ observations.

3.2. Impact of Argo on Salinity Reanalysis. Since no "observations" are assimilated in Experiment 1 and the initial field (climatological August salinity) has big difference with the true field (CORA salinity of January 2005), the mean RMSE of salinity over whole domain is about $0.485 \mathrm{psu}$. Similar to that of temperature analysis, the largest RMSEs of salinity appear in China coastal water, Thailand Bay, and Karimata Strait where few "observations" can support the analysis. Luzon Strait, area to the east of Taiwan, Japan Sea, and Equator area also have large RMSEs (Figure 4(a)). By assimilating 


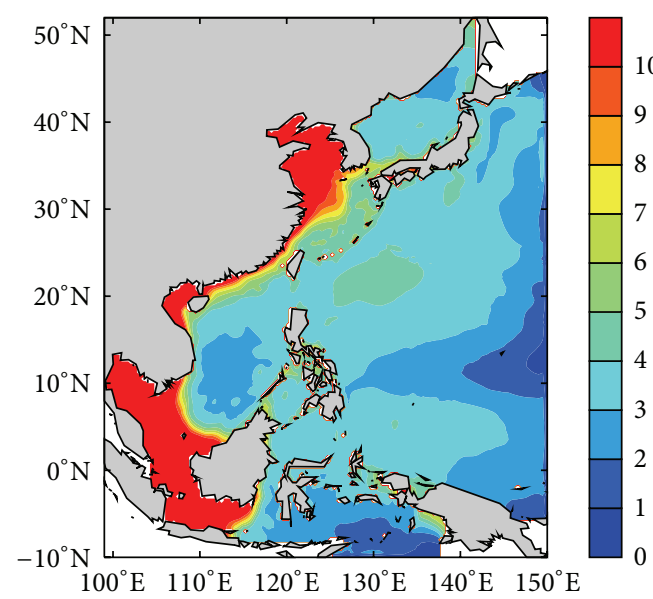

(a)

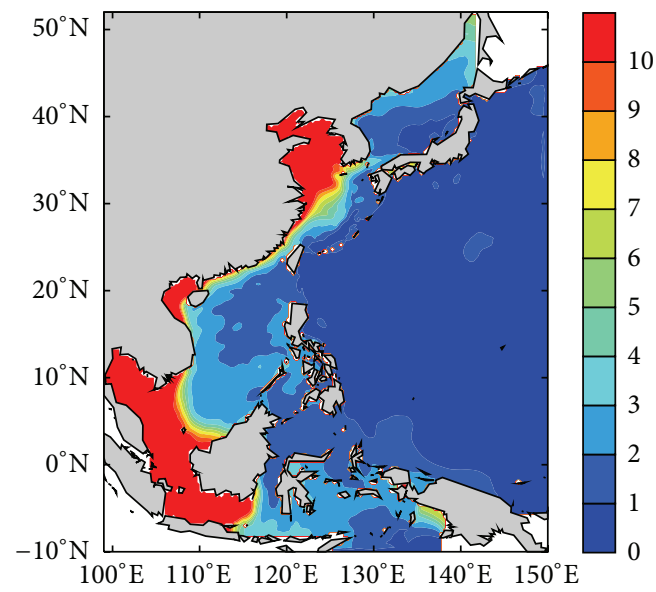

(c)

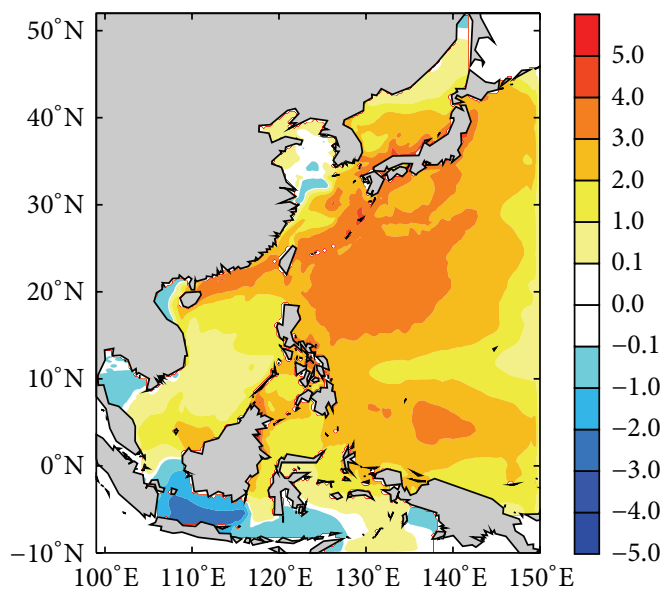

(e)

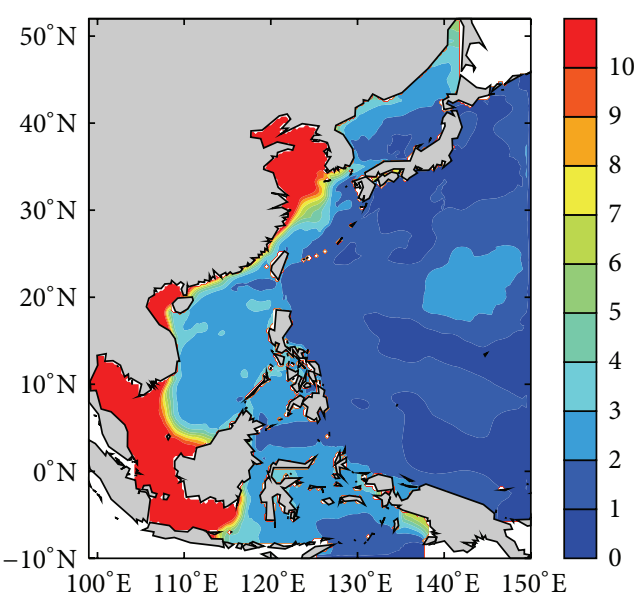

(b)

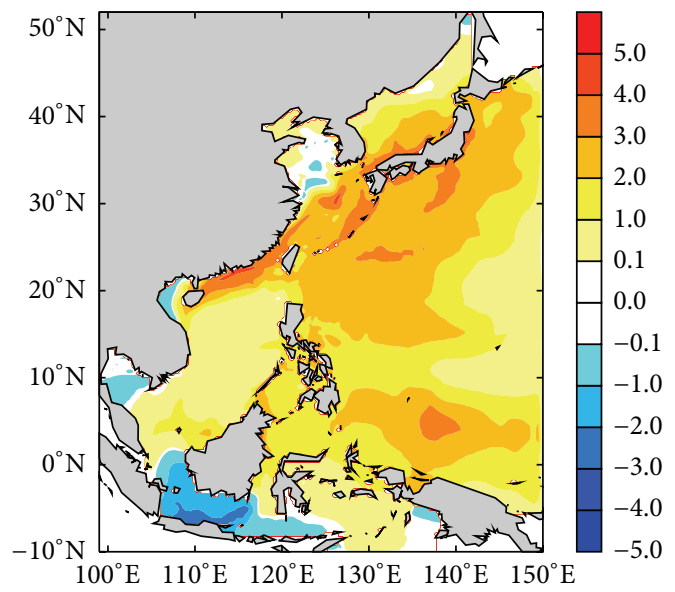

(d)

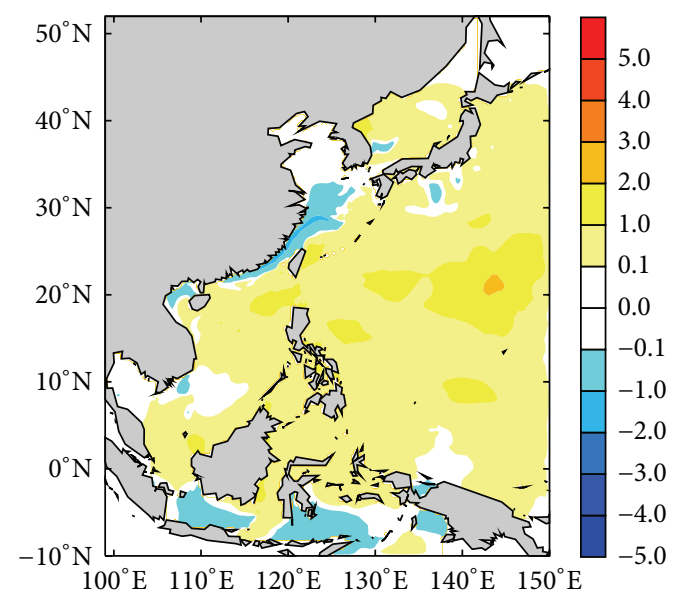

(f)

FIGURE 2: (a), (b), and (c) show the horizontal distribution of vertical averaged temperature RMSEs of three twin-experiments, respectively, using (2); (d) shows the difference of temperature RMSEs between Experiments 2 and 1, that is, Experiment 1 minus Experiment 2, and (e) is for Experiment 1 minus Experiment 3; (f) is for Experiment 2 minus Experiment 3. Unit: ${ }^{\circ} \mathrm{C}$. Experiment 1 is a free run where no data is assimilated, while Experiment 2 only assimilates "conventional observations" and Experiment 3 assimilates all the "observations" including "conventional observations" and "Argo observations." 


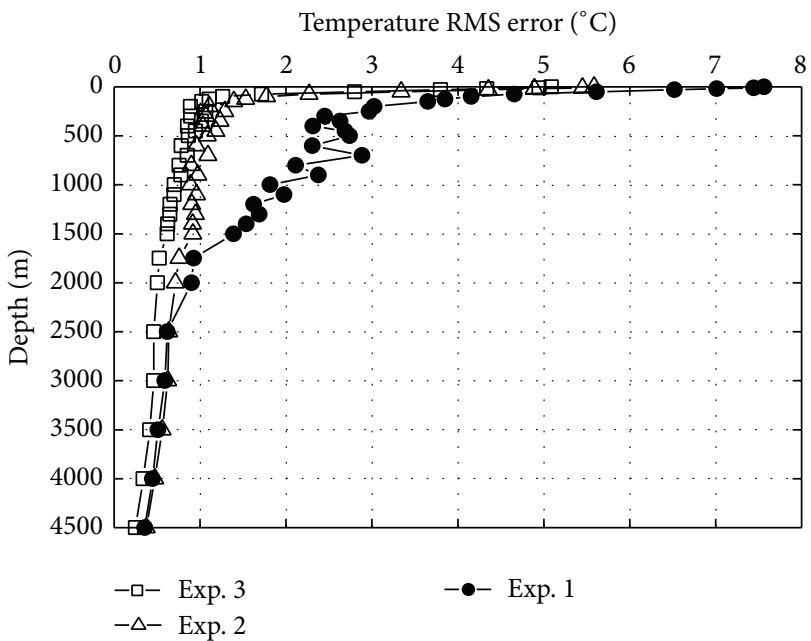

(a)

Exp. 1-Exp. 3

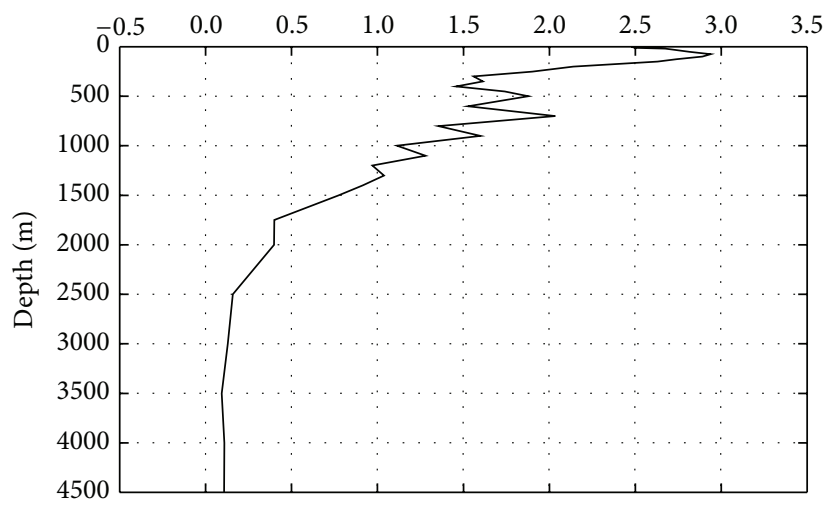

(c)

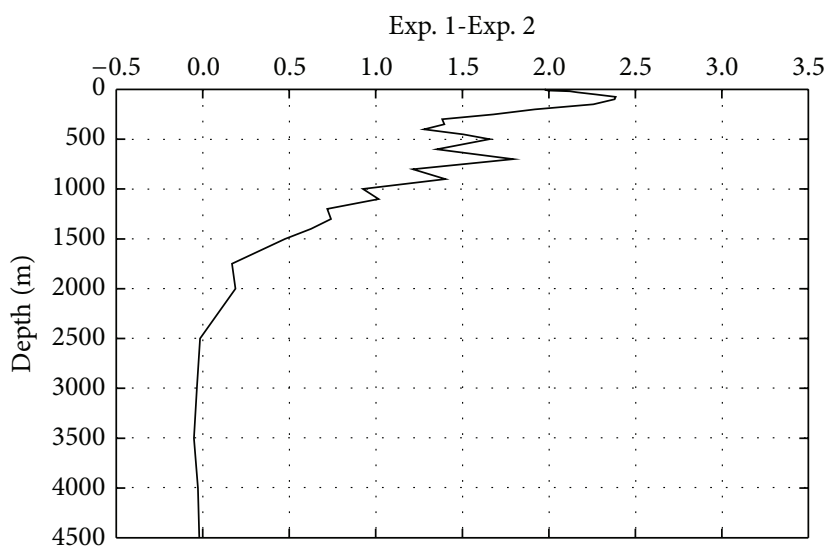

(b)

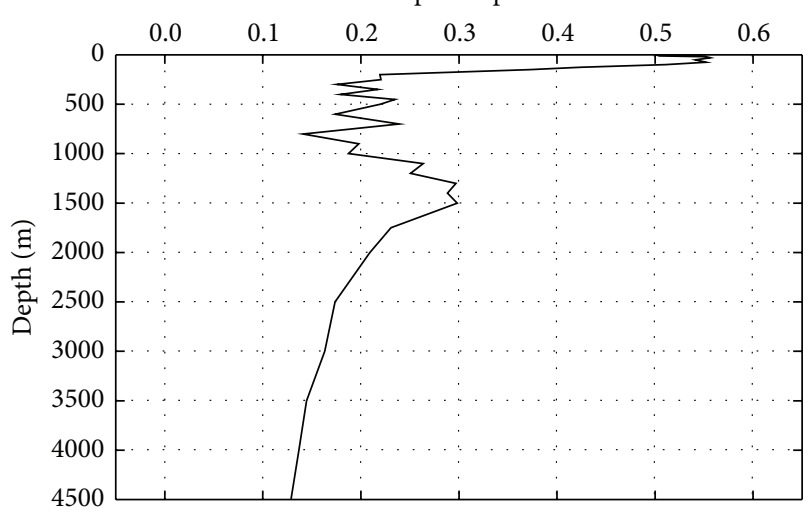

(d)

FIgURE 3: (a) The vertical structure of temperature RMSE of Experiments 1 (solid line with solid circle), 2 (solid line with hollow up-triangle), and 3 (solid line with hollow square) using (3); (b) the temperature RMSE of Experiment 1 minus that of Experiment 2; (c) is for Experiment 1 minus Experiment 3; (d) is for Experiment 2 minus Experiment 3. Unit: ${ }^{\circ} \mathrm{C}$.

“conventional observations," salinity RMSE of Experiment 2 is obviously lower than that of Experiment 1 by about $25 \%$. By further assimilating "Argo observations," the salinity RMSE of Experiment 3 is lower than that of Experiment 2 by about $10 \%$; that is, the salinity RMSE of Experiment 3 is lowest among all the three twin experiments. It is found that the improved area of Experiment 2 compared to 1 includes Japan Sea, Kuroshio to the south of Japan, and area to the east of Taiwan where many "observations" can support the analysis (Figure 4(d)). Besides the above improved area, the improved area of Experiment 3 compared to 1 is further enlarged (Figure 4(e)). It can be seen from Figure 4(f), as a necessary kind of supplement to "conventional observations," salinity data assimilation of "Argo observation" can significantly improve the salinity analysis to the east of Luzon Strait and the western part of Japan Sea. From the vertical structure of salinity RMS error of these three twin experiments (Figure 5(a)) and for the similar reason as that for temperature, the maximum RMSE is at surface, but another obvious extreme exists between $500 \mathrm{~m}$ and $1000 \mathrm{~m}$ in Experiment 1. Different from that of temperature, although salinities in all levels are improved not only in Experiment 3 (Figure 5(c)) but also in Experiment 2 (Figure 5(b)), the maximum improvement concentrates in the middle level between $500 \mathrm{~m}$ and $1000 \mathrm{~m}$ (Figure 5(d)). Large RMSE in upper $300 \mathrm{~m}$ ocean mainly comes from the continental shelf (Figure 4(a)), where almost no salinity observation exists. Therefore, only a little improvement is found in the upper $300 \mathrm{~m}$ ocean in both Experiments 2 and 3, and Argo does not provide additional useful information to improve the salinity reanalysis on continental shelf. However, in the interior ocean, especially in the area with depth deeper than $1000 \mathrm{~m}$, Argo can provide additional useful salinity observations, which can improve salinity reanalysis significantly.

3.3. Impact of Argo on Current Reanalysis. Since this study assimilates temperature and salinity "observations" rather than velocity "observations," true velocity field can be added in the verification of reanalysis as an independent element (Figure 6). For both U component and V component, 


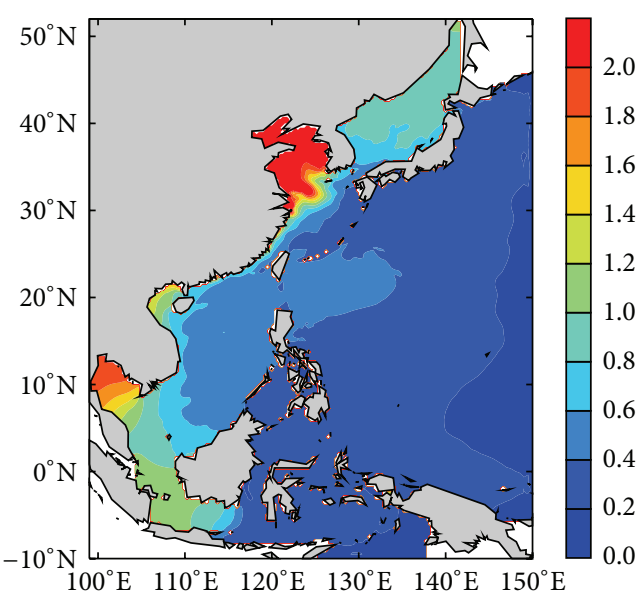

(a)

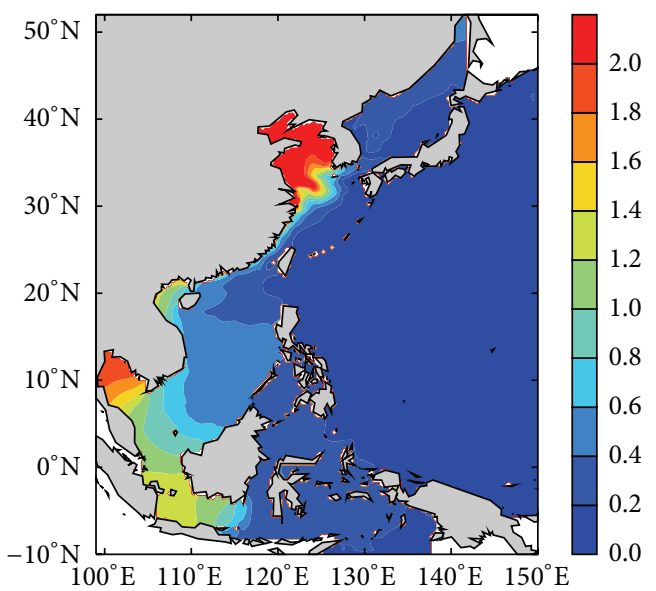

(c)

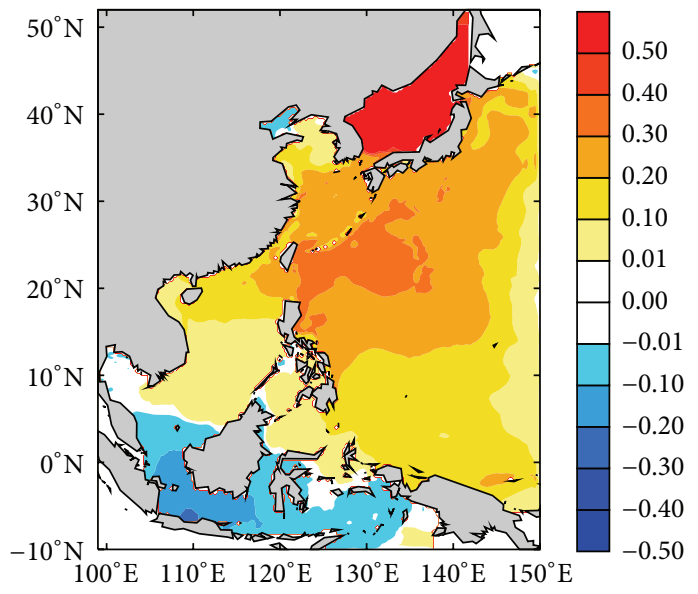

(e)

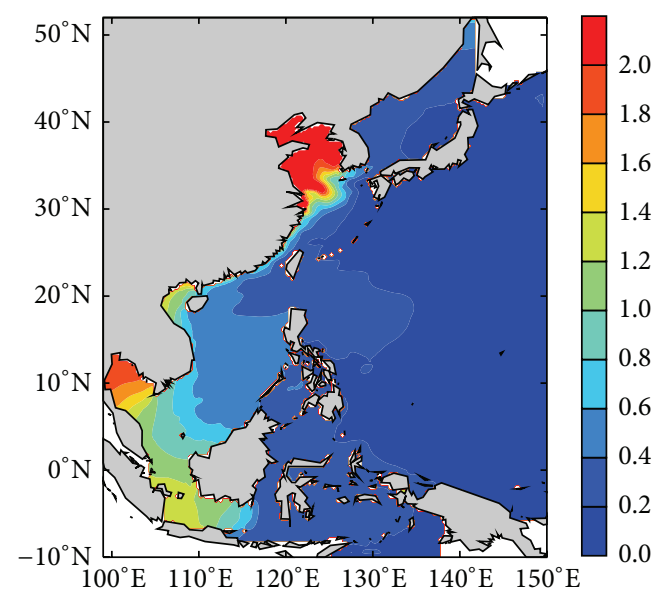

(b)

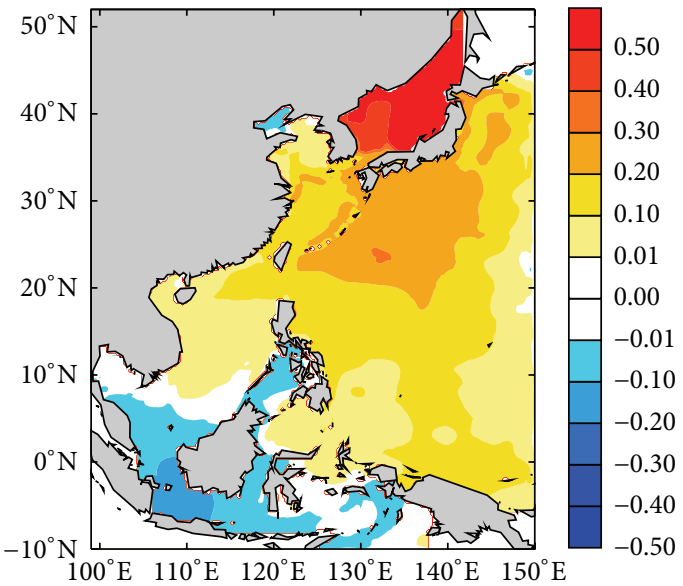

(d)

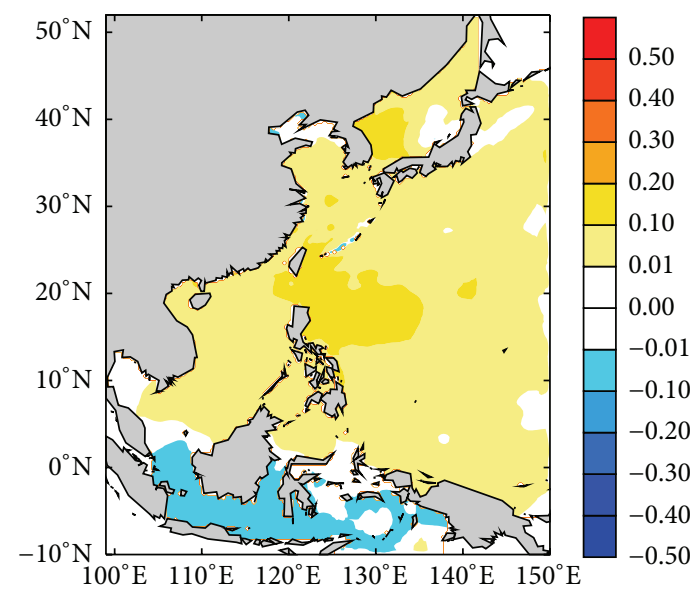

(f)

FIgURE 4: Similar to Figure 3 but for salinity. Unit: psu.

the RMSE of Experiment 1 is the biggest among these three twin experiments and that of Experiment 3 is the smallest. For $\mathrm{U}$ component, the RMSEs of these three twin experiments are $0.112 \mathrm{~m} / \mathrm{s}, 0.089 \mathrm{~m} / \mathrm{s}$, and $0.069 \mathrm{~m} / \mathrm{s}$, respectively. By assimilating "conventional observations," U component RMSE of
Experiment 2 is obviously lower than that of Experiment 1 by about $20 \%$. By further assimilating "Argo observations," the U component RMSE of Experiment 3 is lower than that of Experiment 2 by about $18 \%$. For V component, the RMSEs of these three twin experiments are $0.094 \mathrm{~m} / \mathrm{s}, 0.083 \mathrm{~m} / \mathrm{s}$, 


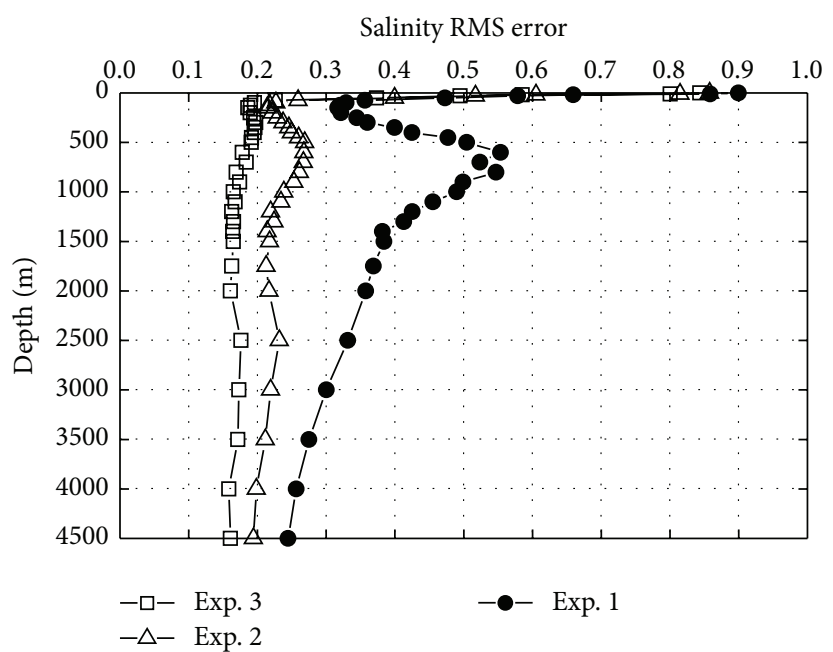

(a)

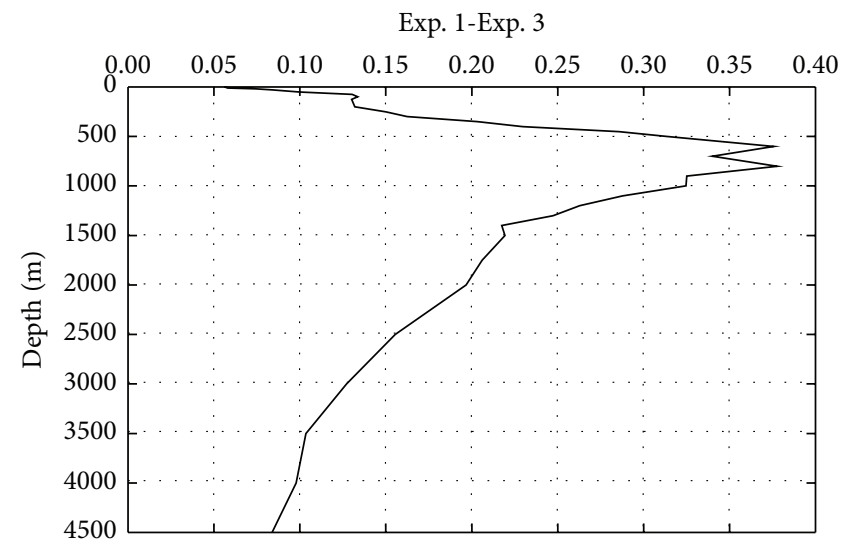

(c)

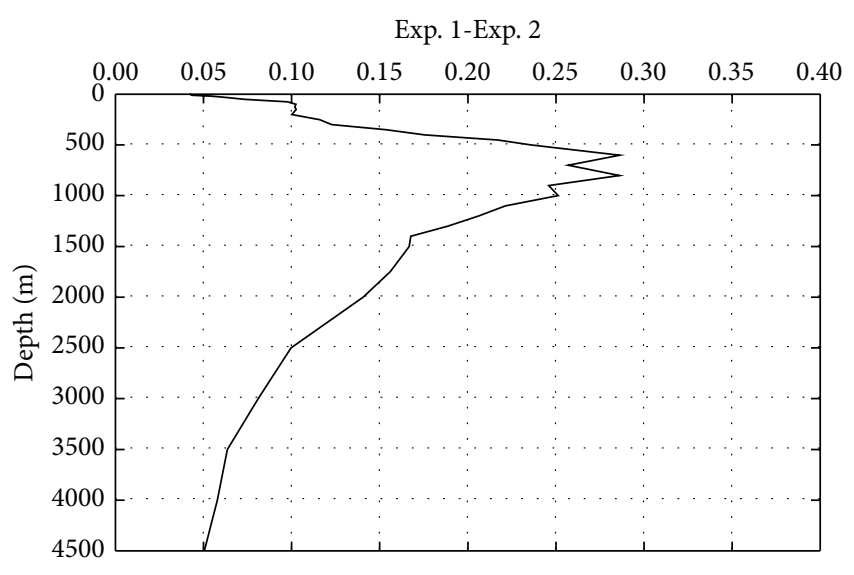

(b)

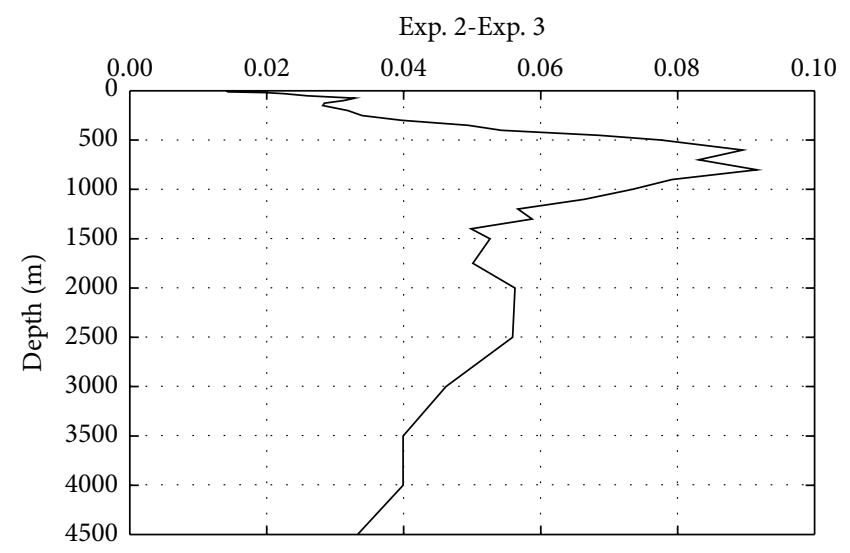

(d)

FIgURE 5: Similar to Figure 4 but for salinity. Unit: psu.

and $0.065 \mathrm{~m} / \mathrm{s}$, respectively. By assimilating "conventional observations," V component RMSE of Experiment 2 is obviously lower than that of Experiment 1 by about $12 \%$. By further assimilating "Argo observations," the V component RMSE of Experiment 3 is lower than that of Experiment 2 by about 19\%. Zonal flow dominates the World Ocean; however Kuroshio, the strong western boundary current, exists in this study domain, so the maximum zonal velocity and the maximum meridional velocity almost share the same value. For $U$ component, it is found that the improvement area of Experiment 2 compared to 1 includes continental shelf area, Kuroshio, and north equator current (Figure 6(d)). Besides the above improved area, the improved area of Experiment 3 compared to 1 further includes the northwest Pacific Ocean (Figure 6(e)). The major improved area of $\mathrm{U}$ component by further assimilating "Argo observations" concentrates in west Pacific Ocean (Figure 6(f)). For V component, the improved area of Experiment 2 compared to 1 focuses on the strong current area (Figure 6(j)), which is different from that of $U$ component. The major improved area of V component by further assimilating "Argo observations" concentrates in west Pacific Ocean (Figure 6(1)), which is similar to that of $\mathrm{U}$ component. From Figures 7 and 8, the main improvements locate above the $2000 \mathrm{~m}$ level and beneath $2500 \mathrm{~m}$ level. In Experiment 2, between $2000 \mathrm{~m}$ and $2500 \mathrm{~m}$, there is almost no improvement for $\mathrm{V}$ component and somewhat degeneration for $\mathrm{U}$ component. However, in Experiment 3 with "Argo observation" assimilated, $U$ and $\mathrm{V}$ components for all levels are improved, and relative to Experiment 2 the main improvement concentrates in the upper $1500 \mathrm{~m}$ levels. The horizontal scale of the study domain is large and current velocity of most area in this study domain is small; therefore, except shallow sea, such as coastal water, geostrophic or quasigeostrophic approximation is a reasonable way for estimating current field. And under this approximation, distribution of velocity field to the first order can be determined by density field on large scale. Since the density is determined by temperature and salinity, the obvious improvement on temperature and salinity may result in the improvement on density and may sequentially result in the improvement of velocity field.

It is worth noting that although Argo profiles are mainly distributed in Pacific Ocean to the east of Ryukyu Island in this study domain, Argo data assimilation obviously 


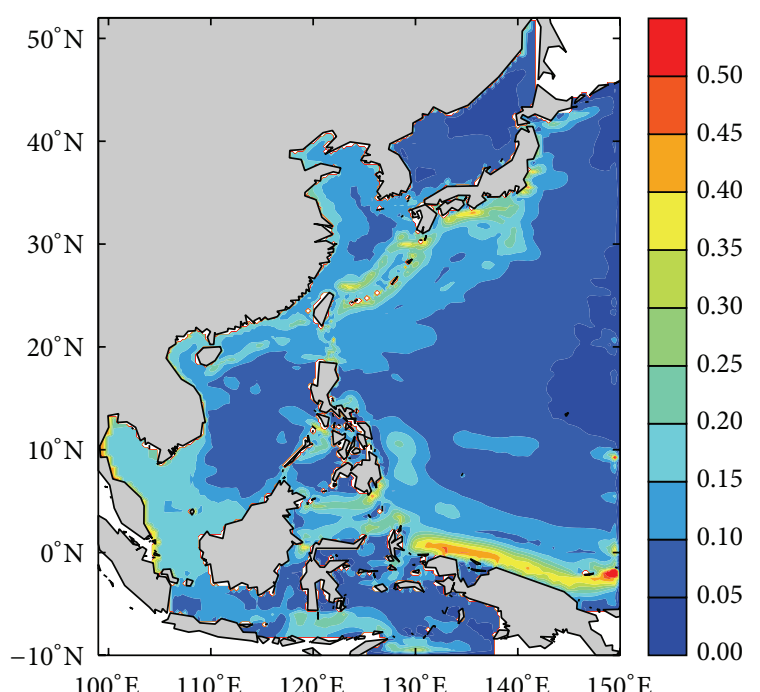

(a)

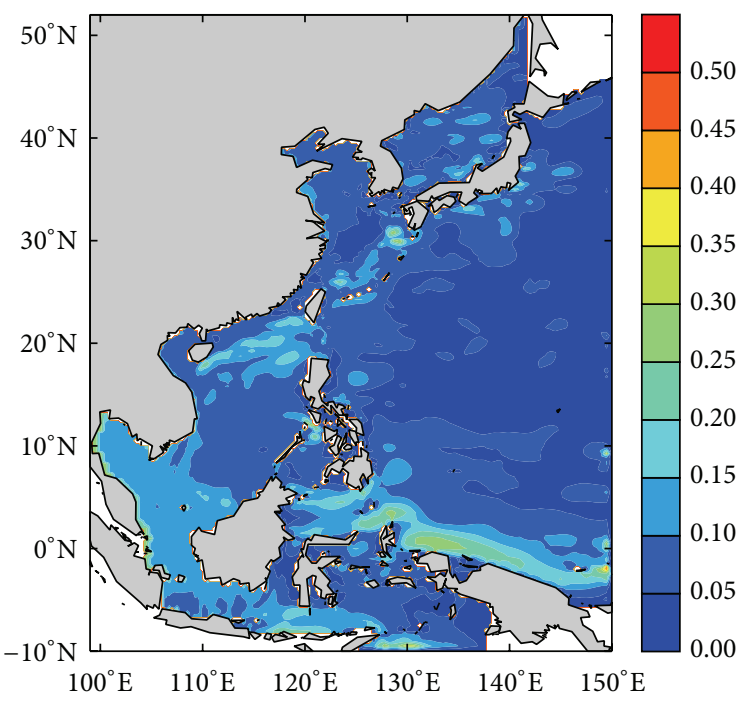

(c)

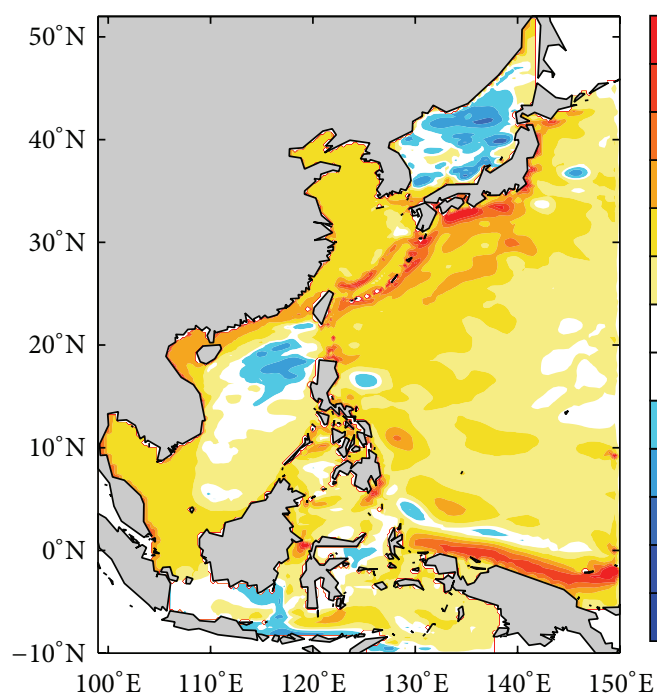

(e)

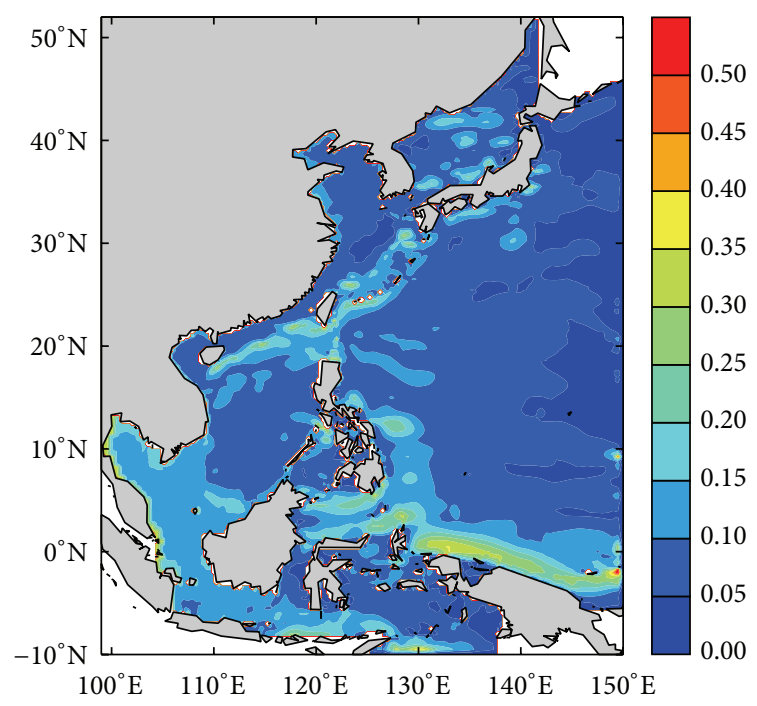

(b)

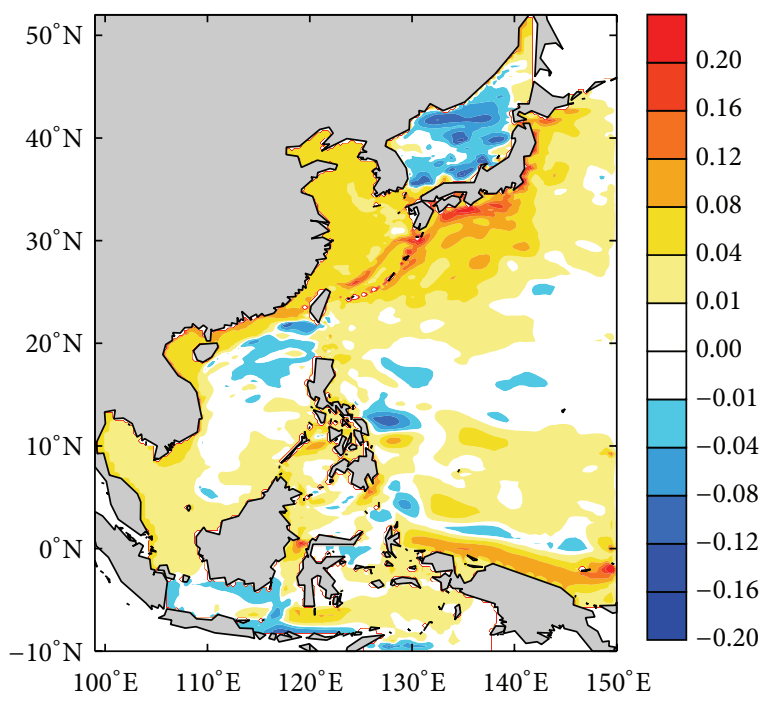

(d)

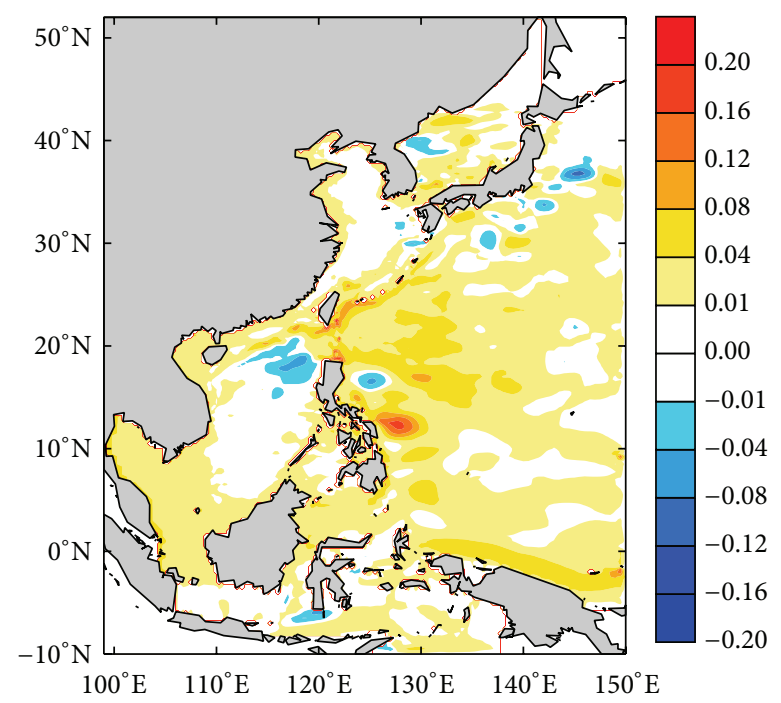

(f)

Figure 6: Continued. 


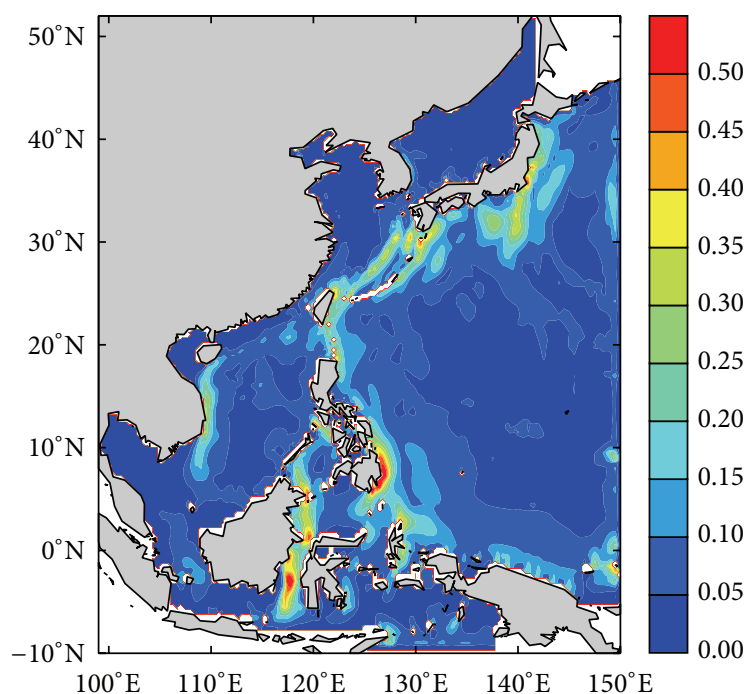

(g)

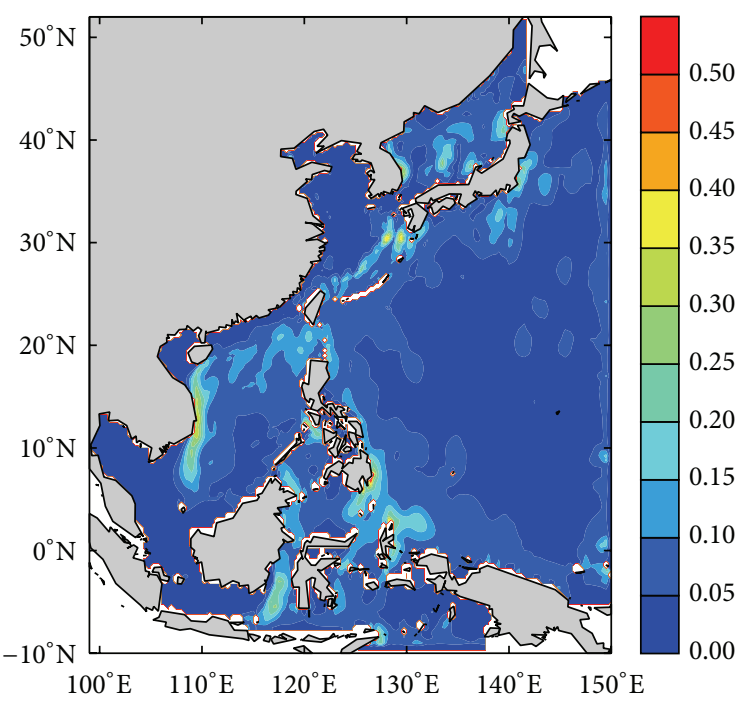

(i)

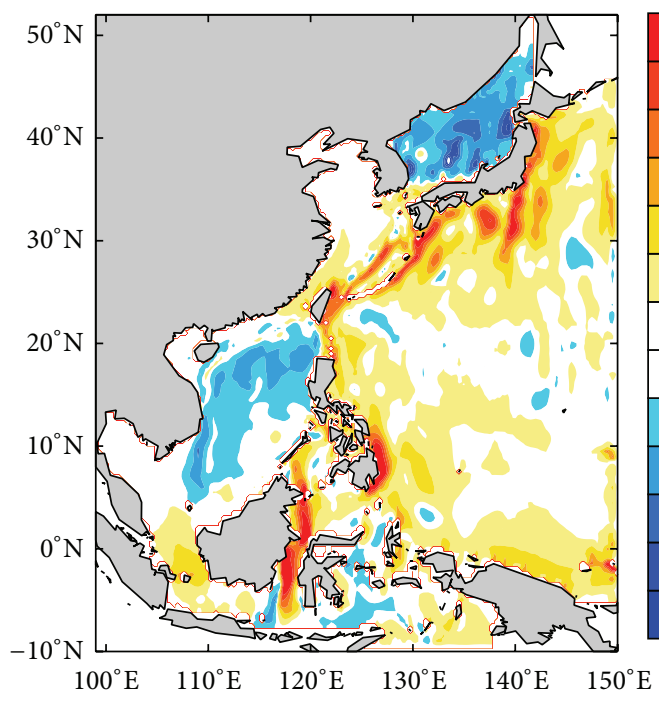

(k)

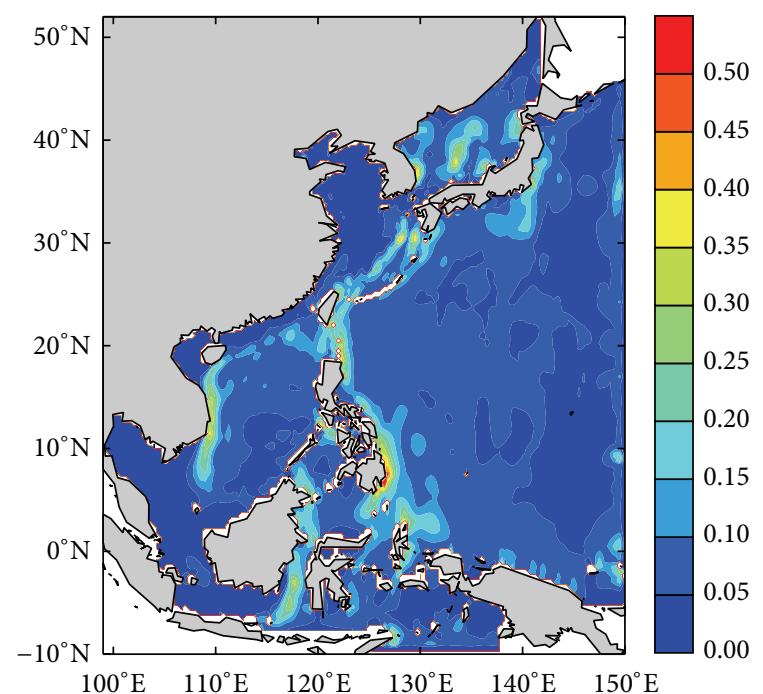

(h)

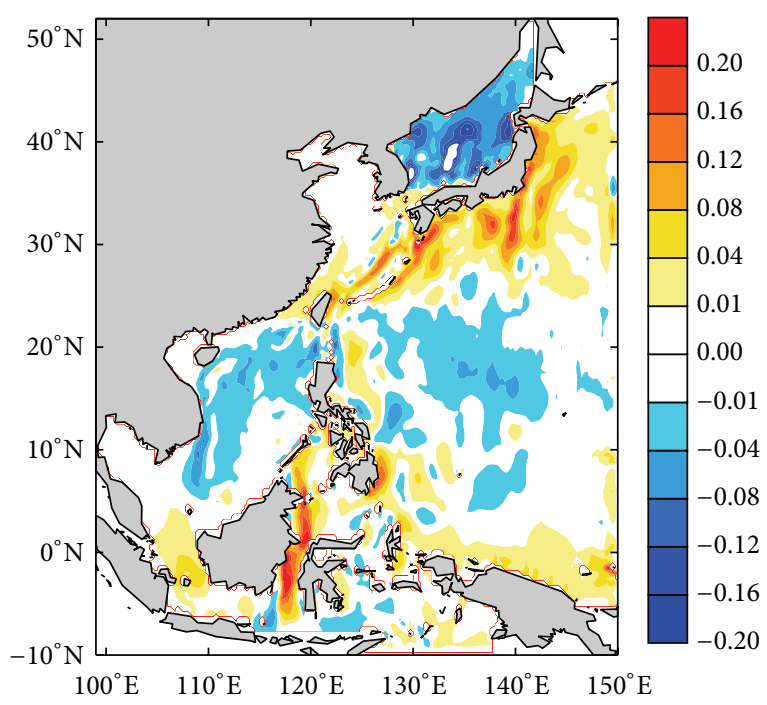

(j)

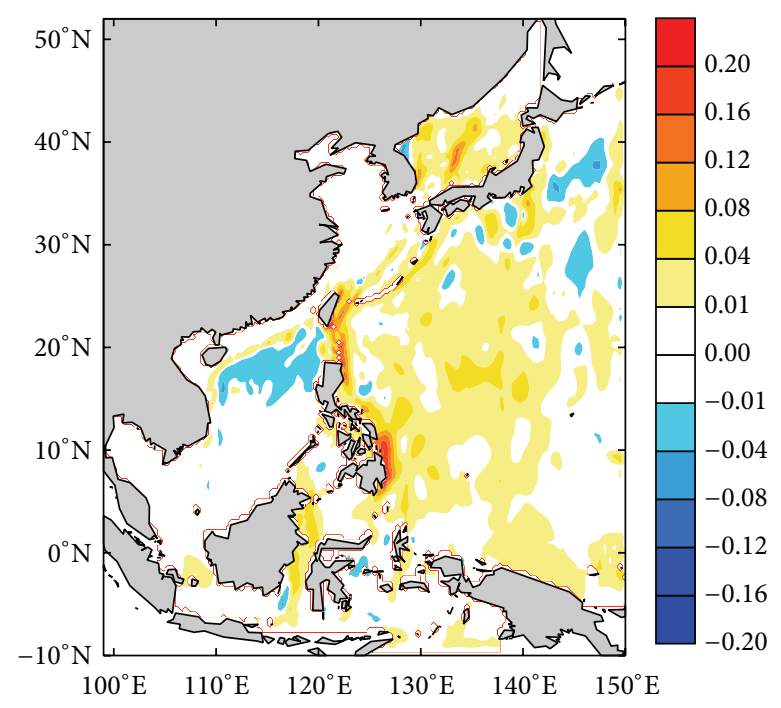

(1)

Figure 6: (a)-(f) are similar to Figure 3 but for $\mathrm{U}$ component and (g)-(l) are similar to Figure 3 but for $\mathrm{V}$ component. Unit: $\mathrm{m} / \mathrm{s}$. 


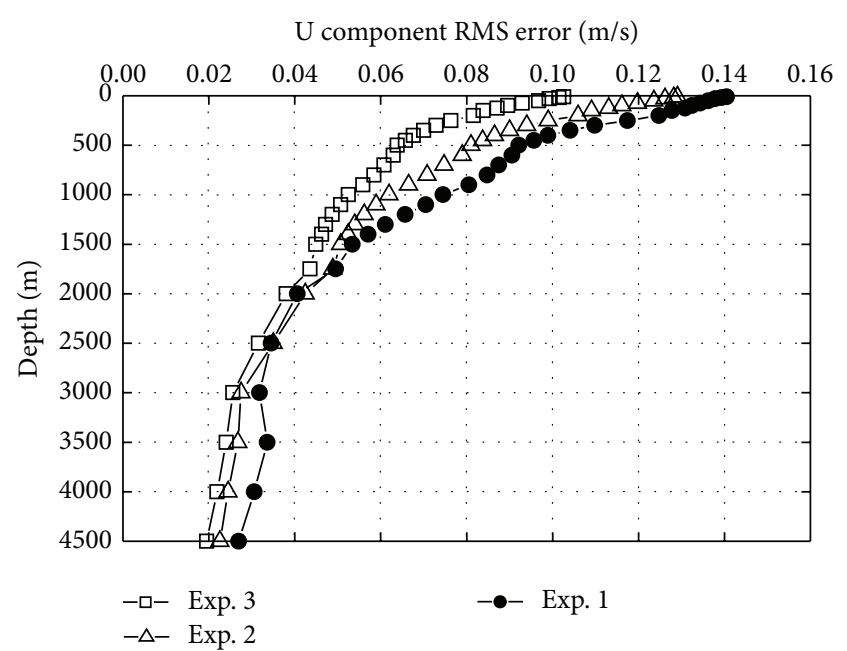

(a)

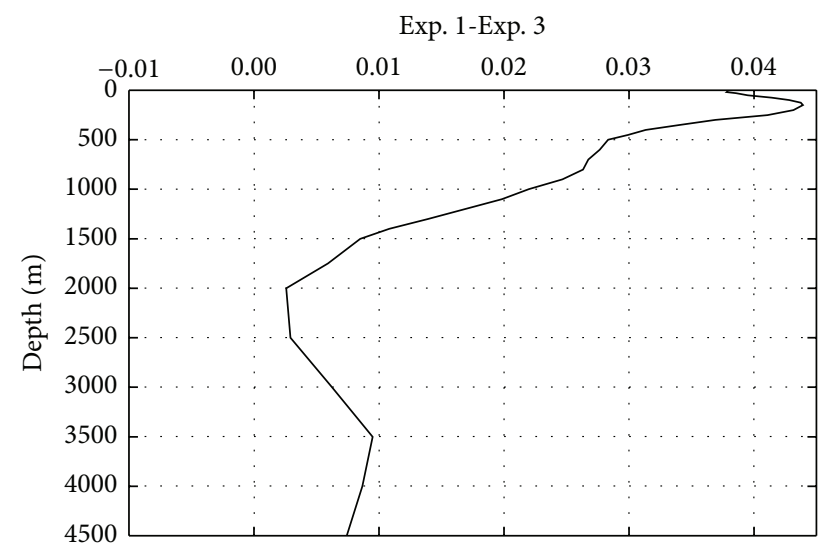

(c)

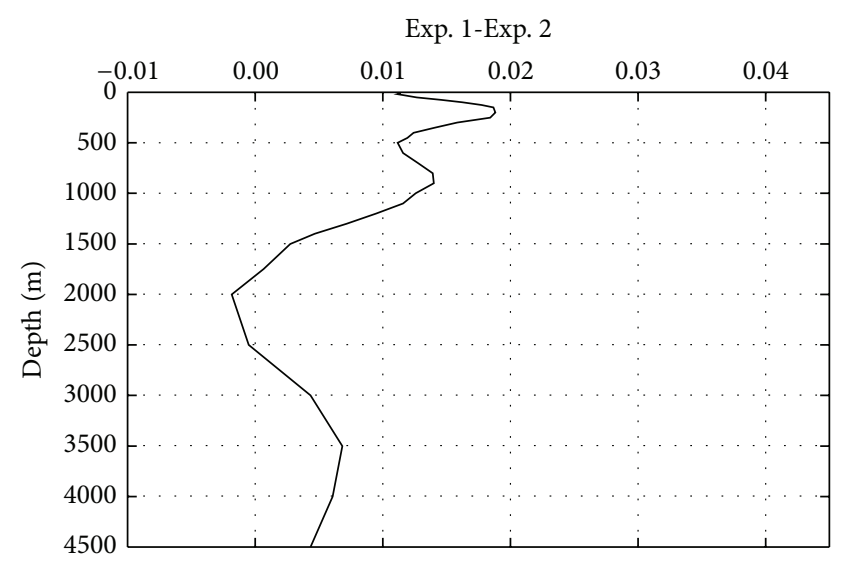

(b)

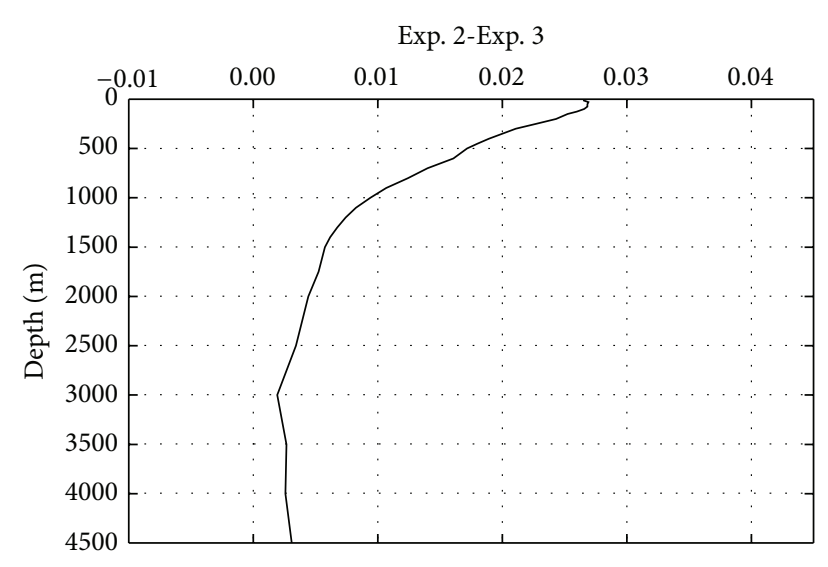

(d)

Figure 7: Similar to Figure 4 but for U component.

improved the Kuroshio transport of East China Sea to the west of Ryukyu Island. Figure 9 gives the time series of the differences of the Kuroshio transport at PN section of East China Sea between these three twin experiments and the truth. The $\mathrm{PN}$ line is an important section which is about from $\left(124.5^{\circ} \mathrm{E}, 30^{\circ} \mathrm{N}\right)$ to $\left(128.23^{\circ} \mathrm{E}, 27.45^{\circ} \mathrm{N}\right)$, and oceanographic data obtained along this section are the most significant in the investigation of Kuroshio in East China Sea [32]. Diagnosed from temperature and salinity observation at PN section, the average of observed $\mathrm{PN}$ relative geostrophic volume transport is about $25.8 \mathrm{~Sv}$, with a mean seasonal maximum of $27.0 \mathrm{~Sv}$ in summer and minimum of $23.9 \mathrm{~Sv}$ in autumn [32]. In our true field, the averaged PN transport is about $26.5 \mathrm{~Sv}$, and in 2007 the maximum is $29.7 \mathrm{~Sv}$ occurring in summer and the minimum is $23.3 \mathrm{~Sv}$ occurring in autumn, which is basically consistent with the observation. Due to the bad initial condition which may significantly deteriorate the Kuroshio analysis and simulation, the RMSE of Kuroshio transport in Experiment 1 is $15.1 \mathrm{~Sv}$, while that in Experiment 2 with conventional observations data assimilated reduced to $4.4 \mathrm{~Sv}$ and that in Experiment 3 with all observations data assimilated further reduced to $2.9 \mathrm{~Sv}$. Compared with
Experiment 2, further assimilation of Argo profile may improve the reanalysis accuracy of Kuroshio transport by about $1.5 \mathrm{~Sv}$ and speed up the current simulation toward the true field. The reason may be that since Argo data assimilation can improve the current field of Pacific Ocean to the east of Ryukyu Island which is the open boundary condition of marginal sea current field, the improvement in Pacific Ocean circulation may successively improve the marginal sea current field including the western boundary current such as Kuroshio due to the continuity of fluid. Argo profiles are widely distributed in World Ocean, so the ocean circulation field can be significantly improved by assimilating Argo.

\section{Conclusion}

In this paper, based on the CORA system, three twin experiments are used to evaluate the impact of Argo data on temperature, salinity, and current reanalysis results. The main conclusions can be drawn as follows.

(1) As a necessary kind of supplement to conventional temperature and salinity observations, Argo data 


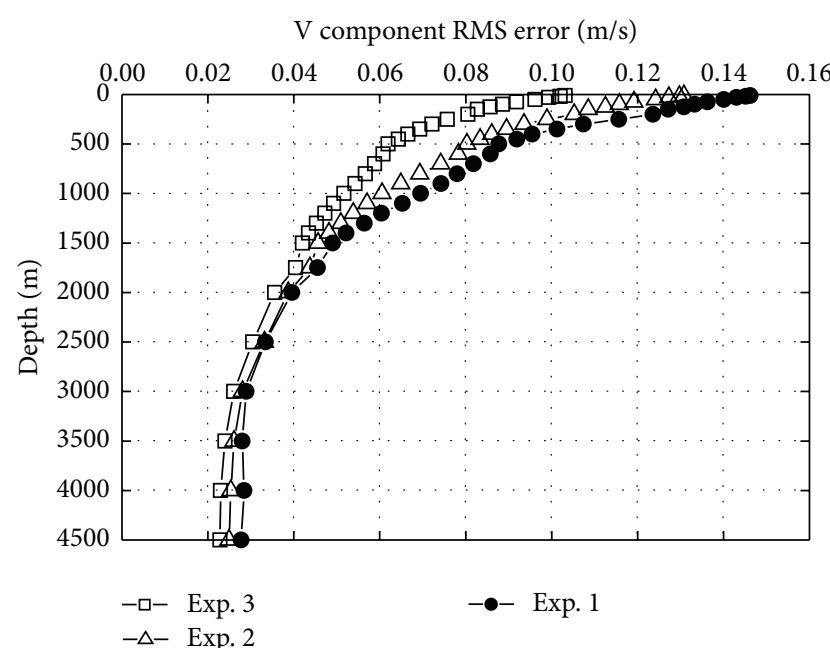

(a)

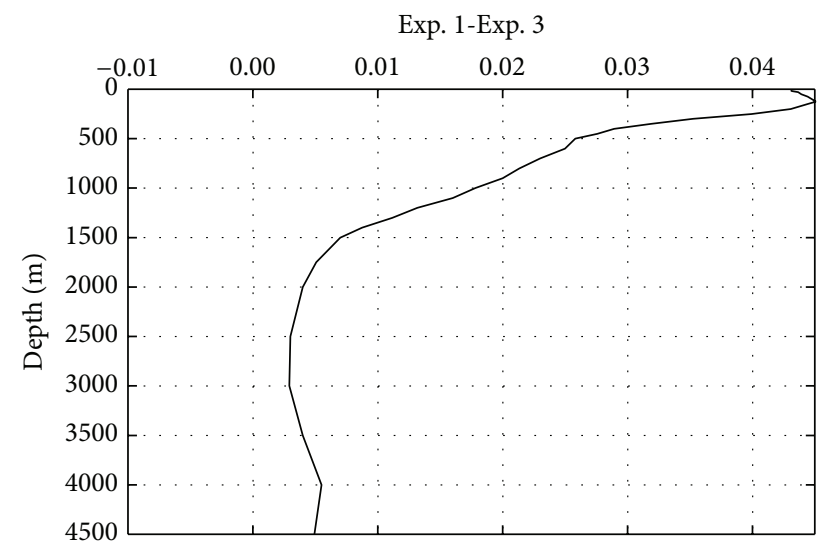

(c)

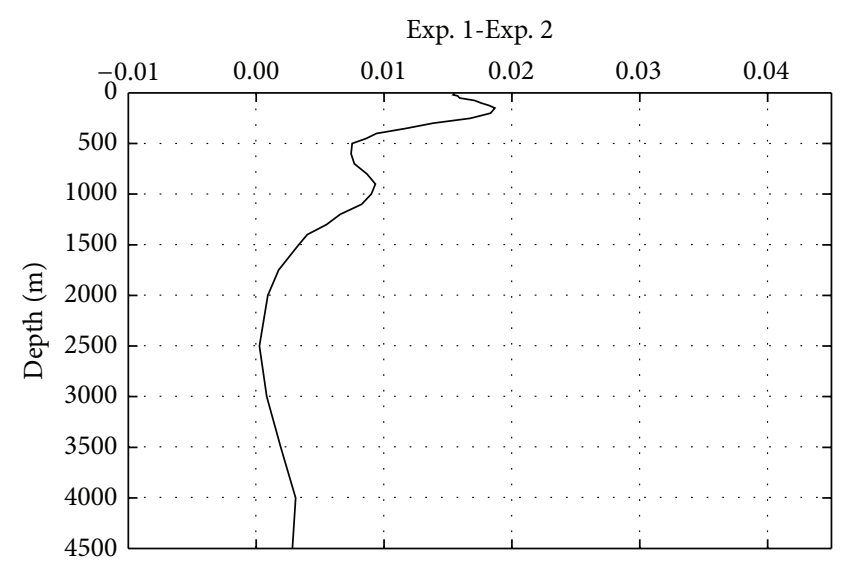

(b)

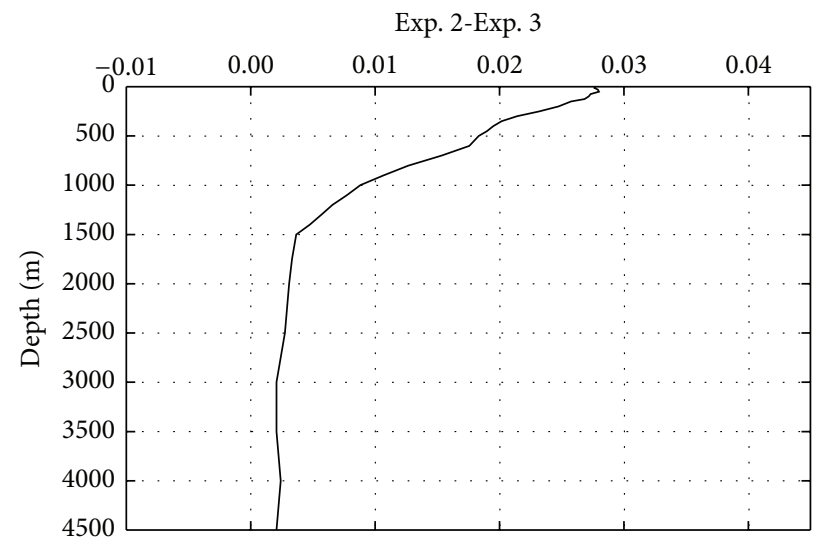

(d)

FIgURE 8: Similar to Figure 4 but for V component.

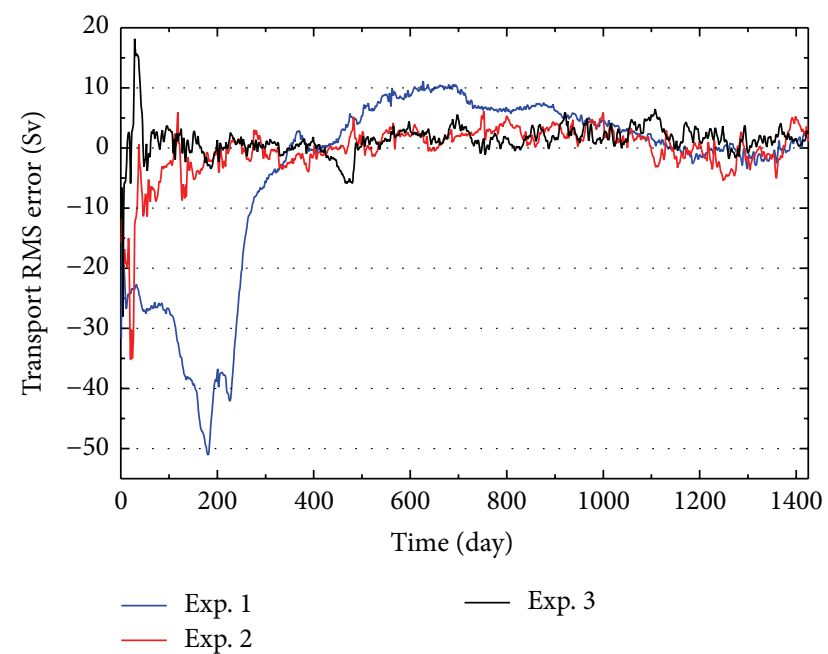

FIgURE 9: Time series of the differences of the Kuroshio transport at PN section of East China Sea between the three twin experiments and the truth obtained from the control run. Blue line is for Experiment 1 minus the truth, red line is for Experiment 2 minus the truth, and black line is for Experiment 3 minus the truth. assimilation can further improve the reanalysis accuracy of temperature and salinity which have been improved by assimilating only conventional observations and further enlarge the improved area. With Argo profiles assimilated, the RMSEs of temperature and salinity reanalysis can be further reduced by about $10 \%$ in our study domain. Consistent with the unique feature of Argo observations, the temperature is improved in all levels and the largest improvement of salinity happens in the deep ocean.

(2) Velocity field can be determined by density field in large scale to the first order under geostrophic or quasigeostrophic approximation; therefore, as long as temperature and salinity can be improved by data assimilation, density structure and the corresponding velocity field can be improved. Argo profiles are widely distributed in World Ocean, so the ocean circulation field can be significantly improved by assimilating Argo. With Argo profiles assimilated, the RMS errors of current reanalysis can be further reduced by about $18 \%$ in our study domain. 


\section{Conflict of Interests}

The authors declare that there is no conflict of interests regarding the publication of this paper.

\section{Acknowledgments}

The authors would like to express their gratitude to two reviewers for their helpful comments and suggestions, which contributed to great improvement of the original paper. This research was jointly supported by grants of National Basic Research Program (2013CB430304), National Natural Science Foundation (41176003, 41206178, 41376013, 41376015, and 41306006), National High-Tech R\&D Program (2013AA09A505), and Global Change and Air-Sea Interaction (GASI-01-01-12) of China.

\section{References}

[1] D. Roemmich and Argo Science Team, "Argo: the global array of profiling floats," in Observing the Oceans in the 21st Century, C. J. Koblinsky and N. R. Smith, Eds., pp. 248-257, GODAE Project Office/Bureau of Meteorology, Melbourne, Australia, 2001.

[2] J. A. Carton and B. S. Giese, "A reanalysis of ocean climate using Simple Ocean Data Assimilation (SODA)," Monthly Weather Review, vol. 136, no. 8, pp. 2999-3017, 2008.

[3] M. A. Balmaseda, A. Vidard, and D. L. T. Anderson, "The ECMWF ocean analysis system: ORA-S3," Monthly Weather Review, vol. 136, no. 8, pp. 3018-3034, 2008.

[4] E. J. Metzger, O. M. Smedstad, P. G. Thoppil et al., "US Navy operational global ocean and Arctic ice prediction systems," Oceanography, vol. 27, no. 3, pp. 32-43, 2014.

[5] G. J. Han, W. Li, X. F. Zhang et al., "A regional ocean reanalysis system for coastal waters of China and adjacent seas," Advances in Atmospheric Sciences, vol. 28, no. 3, pp. 682-690, 2011.

[6] A. Vidard, D. L. T. Anderson, and M. Balmaseda, "Impact of ocean observation systems on ocean analysis and seasonal forecasts," Monthly Weather Review, vol. 135, no. 2, pp. 409-429, 2007.

[7] M. Balmaseda, D. Anderson, and A. Vidard, "Impact of Argo on analyses of the global ocean," Geophysical Research Letters, vol. 34, no. 16, Article ID L16605, 2007.

[8] P. R. Oke and A. Schiller, "Impact of Argo, SST, and altimeter data on an eddy-resolving ocean reanalysis," Geophysical Research Letters, vol. 34, no. 19, Article ID L19601, 2007.

[9] C. X. Yan, J. Zhu, and G. Q. Zhou, "Impacts of XBT, TAO, altimetry and ARGO observations on the tropical Pacific Ocean data assimilation," Advances in Atmospheric Sciences, vol. 24, no. 3, pp. 383-398, 2007.

[10] B. Huang, Y. Xue, and D. W. Behringer, "Impacts of Argo salinity in NCEP global ocean data assimilation system: the tropical Indian Ocean," Journal of Geophysical Research C: Oceans, vol. 113, no. 8, Article ID C08002, 2008.

[11] A. Schiller, S. E. Wijffels, and G. A. Meyers, "Design requirements for an argo float array in the indian ocean inferred from observing system simulation experiments," Journal of Atmospheric and Oceanic Technology, vol. 21, no. 10, pp. 15981620, 2004.

[12] A. Griffa, A. Molcard, F. Raicich, and V. Rupolo, "Assessment of the impact of TS assimilation from ARGO floats in the
Mediterranean Sea," Ocean Science, vol. 2, no. 2, pp. 237-248, 2006.

[13] F. Raicich, "The assessment of temperature and salinity sampling strategies in the Mediterranean Sea: idealized and real cases," Ocean Science, vol. 2, no. 2, pp. 97-112, 2006.

[14] S. Zhang, M. J. Harrison, A. Rosati, and A. T. Wittenberg, "System design and evaluation of coupled ensemble data assimilation for global oceanic climate studies," Monthly Weather Review, vol. 135, no. 10, pp. 3541-3564, 2007.

[15] N. J. Dunstone and D. M. Smith, "Impact of atmosphere and sub-Surface ocean data on decadal climate prediction," Geophysical Research Letters, vol. 37, no. 2, Article ID L02709, 2010.

[16] G. J. Han, W. Li, X. F. Zhang et al., "A new version of regional ocean reanalysis for coastal waters of China and adjacent seas," Advances in Atmospheric Sciences, vol. 30, no. 4, pp. 974-982, 2013.

[17] S. Zhang, M. J. Harrison, A. T. Wittenberg, A. Rosati, J. L. Anderson, and V. Balaji, "Initialization of an ENSO forecast system using a parallelized ensemble filter," Monthly Weather Review, vol. 133, no. 11, pp. 3176-3201, 2005.

[18] G. L. Mellor, S. Hakkinen, T. Ezer, and R. Patchen, "A generalization of a sigma coordinate ocean model and an intercomparison of model vertical grids," in Ocean Forecasting: Conceptual Basis and Applications, N. Pinard and J. Woods, Eds., pp. 55-72, Springer, Berlin, Germany, 2002.

[19] T. Ezer and G. L. Mellor, "A generalized coordinate ocean model and a comparison of the bottom boundary layer dynamics in terrain-following and in z-level grids," Ocean Modelling, vol. 6, no. 3-4, pp. 379-403, 2004.

[20] M. Zavatarielli and G. L. Mellor, "A numerical study of the Mediterranean Sea circulation," Journal of Physical Oceanography, vol. 25, no. 6, pp. 1384-1414, 1995.

[21] T. Ezer and G. L. Mellor, "Simulations of the Atlantic Ocean with a free surface sigma coordinate ocean model," Journal of Geophysical Research C: Oceans, vol. 102, no. 7, pp. 15647-15657, 1997.

[22] X. F. Zhang, G. J. Han, D. X. Wang, W. Li, and Z. J. He, "Effect of surface wave breaking on the surface boundary layer of temperature in the Yellow Sea in summer," Ocean Modelling, vol. 38, no. 3-4, pp. 267-279, 2011.

[23] X. F. Zhang, G. J. Han, D. X. Wang, Z. A. Deng, and W. $\mathrm{Li}$, "Summer surface layer thermal response to surface gravity waves in the Yellow Sea," Ocean Dynamics, vol. 62, no. 7, pp. 983-1000, 2012.

[24] G. Mellor and A. Blumberg, "Wave breaking and ocean surface layer thermal response," Journal of Physical Oceanography, vol. 34, no. 3, pp. 693-698, 2004.

[25] Y. F. Xie, S. E. Koch, J. A. McGinley, S. Albers, and $\mathrm{N}$. Wang, "A sequential variational analysis approach for mesoscale data assimilation," in Proceedings of the 21st Conference on Weather Analysis and Forecasting/17th Conference on Numerical Weather Prediction, 15B.7, American Meteorological Society, Washington, DC, USA, August 2005, http://ams.confex.com/ams/pdfpapers/93468.pdf.

[26] W. Li, Y. F. Xie, Z. J. He et al., "Application of the multi-grid data assimilation scheme to the China seas' temperature forecast," Journal of Atmospheric and Oceanic Technology, vol. 25, no. 11, pp. 2106-2116, 2008.

[27] W. Li, Y. F. Xie, S.-M. Deng, and Q. Wang, "Application of the multigrid method to the two-dimensional Doppler radar radial 
velocity data assimilation," Journal of Atmospheric and Oceanic Technology, vol. 27, no. 2, pp. 319-332, 2010.

[28] Y. F. Xie, S. E. Koch, J. A. McGinley et al., "A space-time multiscale analysis system: a sequential variational analysis approach," Monthly Weather Review, vol. 139, no. 4, pp. 12241240, 2011.

[29] W. Li and Y. F. Xie, "Multi-grid analysis of the three-dimensional doppler radar radial velocity: idealized cases study," in Proceedings of the 5th International Joint Conference on Computational Sciences and Optimization (CSO '12), pp. 813-816, June 2012.

[30] W. Li, Y. Xie, and G. Han, "A theoretical study of the multigrid three-dimensional variational data assimilation scheme using a simple bilinear interpolation algorithm," Acta Oceanologica Sinica, vol. 32, no. 3, pp. 80-87, 2013.

[31] A. Troccoli, M. A. Balmaseda, J. Segschneider et al., "Salinity adjustments in the presence of temperature data assimilation," Monthly Weather Review, vol. 130, no. 1, pp. 89-102, 2002.

[32] H. Ichikawa and R. C. Beardsley, "The current system in the Yellow and East China Seas," Journal of Oceanography, vol. 58, no. 1, pp. 77-92, 2002. 

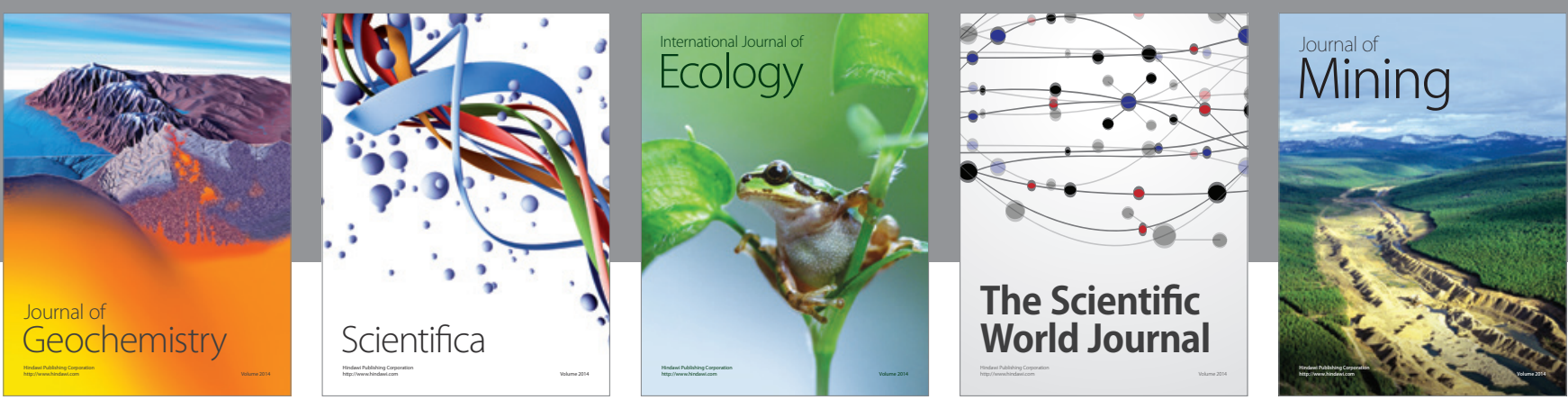

The Scientific World Journal
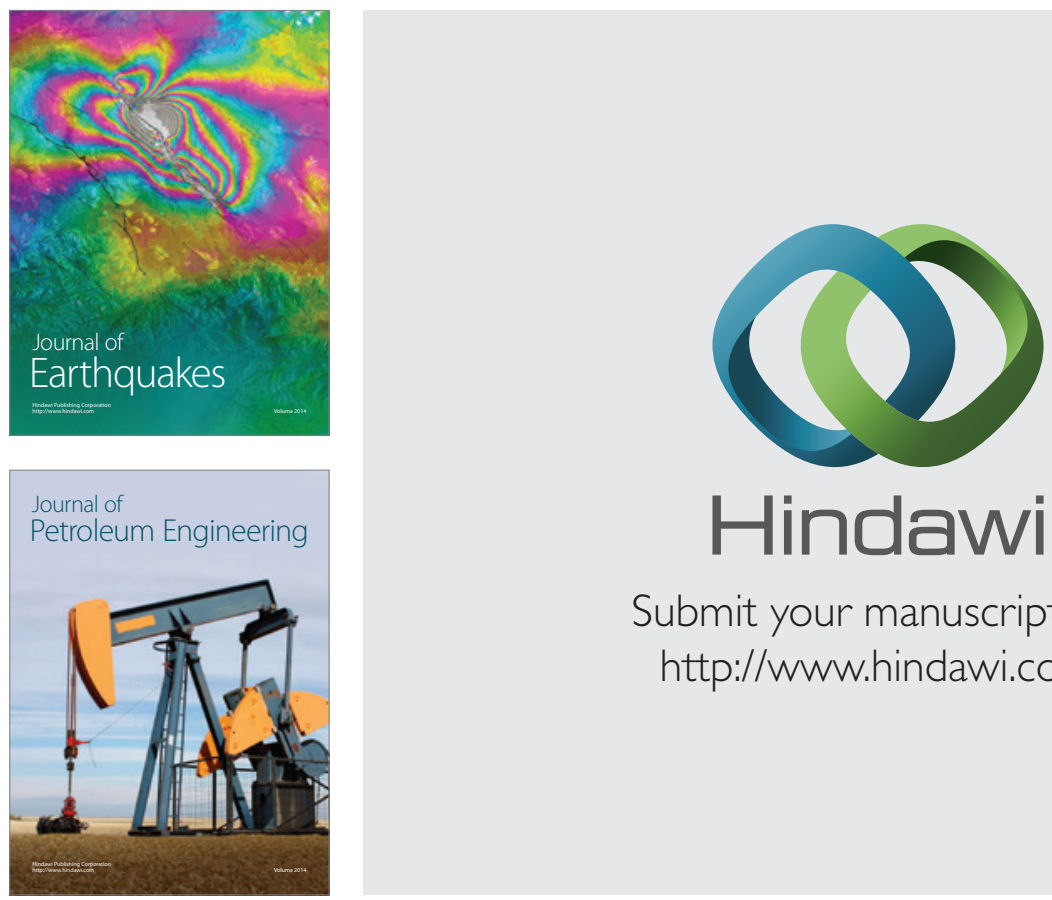

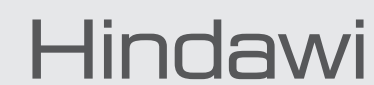

Submit your manuscripts at

http://www.hindawi.com
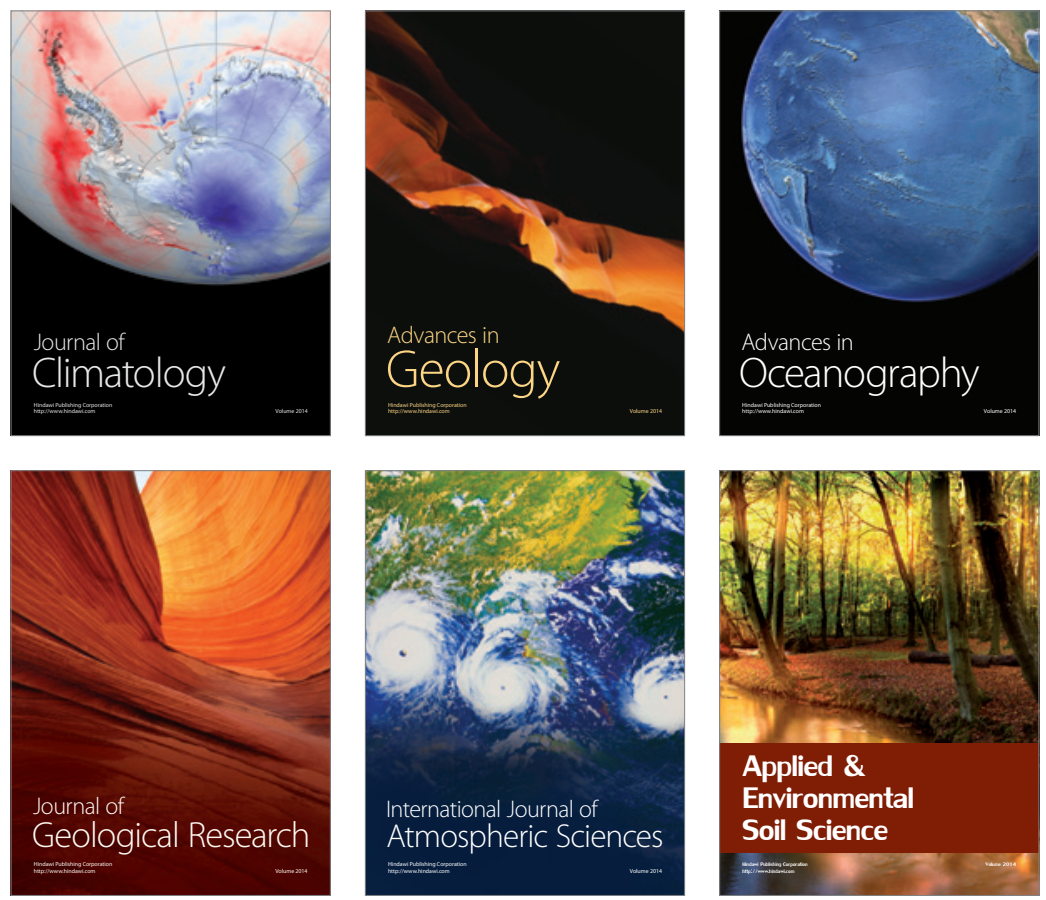
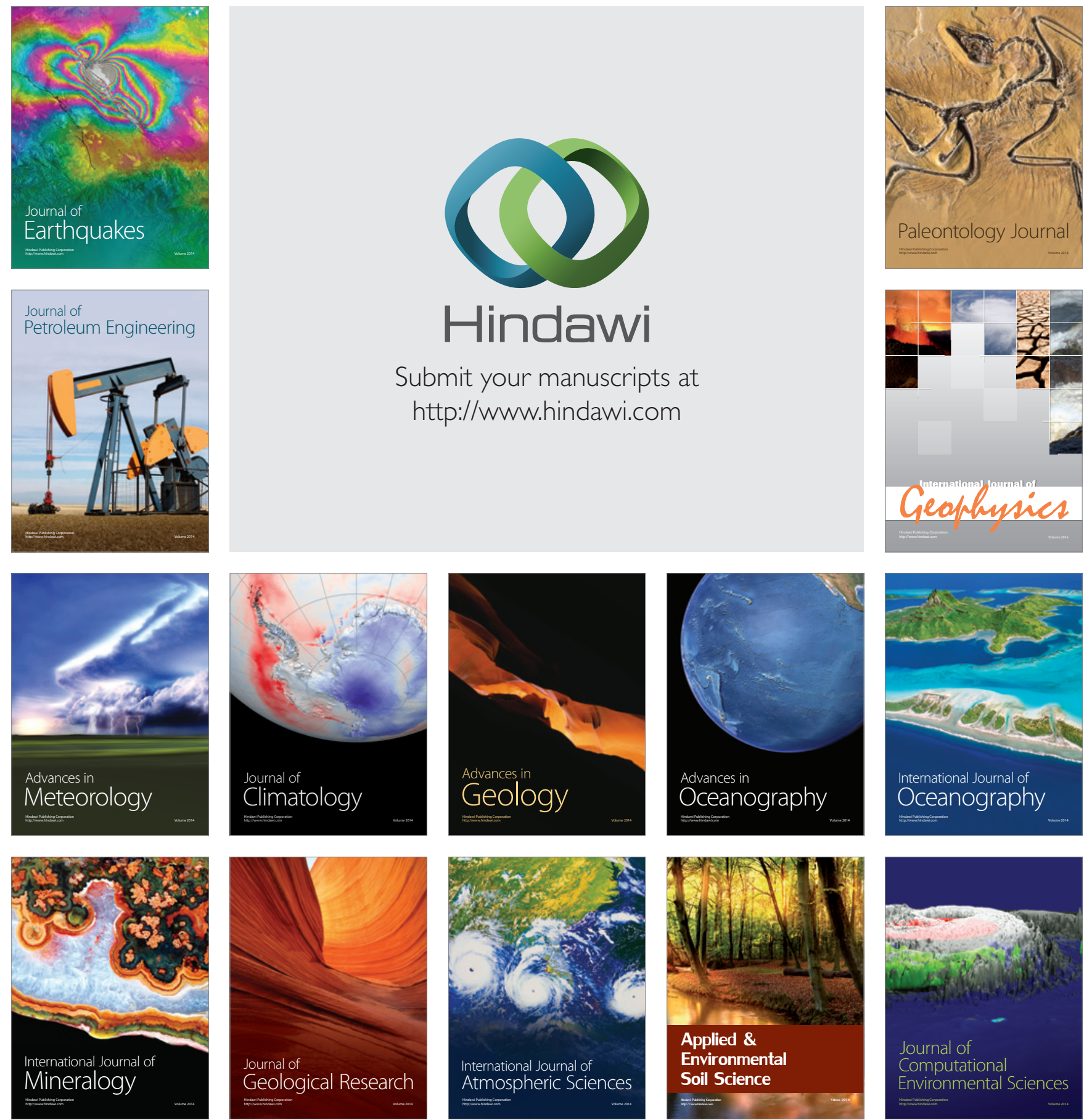